\title{
Simulating the main stages of chalcopyrite leaching and bioleaching in ferrous ions solution: An electrochemical impedance study with a modified carbon paste electrode
}

\author{
Fabiana A. Arena ${ }^{a}$, Patrícia H. Suegama ${ }^{\mathrm{b}}$, Denise Bevilaqua ${ }^{\mathrm{a}}$, Ana L.A. dos Santos ${ }^{\mathrm{a}}$, Cecílio S. Fugivara ${ }^{\mathrm{a}}$, \\ Assis V. Benedetti ${ }^{\mathrm{a}, *}$ \\ a Department of Physical Chemistry, Institute of Chemistry, UNESP, Rua Francisco Degni 55, Quitandinha, 14800-060 Araraquara, SP, Brazil \\ ${ }^{\mathrm{b}}$ Faculty of Exact Sciences and Technology, Federal University of Grande Dourados, Rodovia Dourados-Itahum, km 12, 79804-970 Dourados, MS, Brazil
}

\section{A R T I C L E I N F O}

\section{Article history:}

Received 17 June 2015

Revised 21 March 2016

Accepted 22 March 2016

Available online 29 March 2016

\section{Keywords:}

Carbon paste-chalcopyrite electrode

EIS

Ferrous ions effect

Acidithiobacillus ferrooxidans

\begin{abstract}
A B S T R A C T
In this work, we present an electrochemical study using a carbon paste electrode modified with chalcopyrite $\left(\mathrm{CuFeS}_{2}\right)$ in solution $\mathrm{A}$ of $\mathrm{T} \& \mathrm{~K}$ medium with different ferrous ion concentrations, in the absence and presence of the bacterium Acidithiobacillus ferrooxidans. The aim was to evaluate the influence of ferrous ions and bacteria on the electrochemical behavior of chalcopyrite. Electrochemical impedance spectroscopy (EIS) was used to investigate the processes occurring at the electrode/solution interface in the different systems, considering the charge transfer reactions involving chalcopyrite and ferrous ions, the presence of a multicomponent layer, and diffusion. The main changes in the chalcopyrite response occurred before $67 \mathrm{~h}$ or $43 \mathrm{~h}$ of immersion, in the absence or presence of ferrous ions, respectively, indicating that the surface oxide layer present on chalcopyrite was dissolved faster in the presence of ferrous ions. The addition of bacteria decreased the charge transfer reaction resistance, especially when ferrous ions were present. In the presence of $\mathrm{Fe}^{2+}$, sulfur and jarosite were detected in the solid residues after leaching, while only jarosite was detected in the bioleaching experiment. The results suggested that ferrous ions accelerated the dissolution of chalcopyrite, and that overlayers including biofilms did not halt chalcopyrite dissolution, indicating that there was no passivation.
\end{abstract}

(c) 2016 Elsevier Ltd. All rights reserved.

\section{Introduction}

Copper is increasing in importance worldwide due to its use in the construction and appliance industries. Although the value of the metal varies according to market conditions, investment in exploration activities continues. China is the world's largest consumer of copper, and the largest producer of the metal is Chile. Copper and other metals can be recovered from byproducts of mining using conventional extraction or alternative processes such as biohydrometallurgy, which is mainly employed in metal recovery from low-grade ore and in adverse locations. Microorganisms are used in this process, with the most studied acidophilic bacterium being Acidithiobacillus ferrooxidans, which has been found to be capable of promoting oxidation of the mineral sulfide, hence facilitating metal recovery (Gahan et al., 2012).

The dissolution of several mineral sulfides has been studied, and the formation of new phases is widely reported in the

\footnotetext{
* Corresponding author.

E-mail addresses: benedeti@iq.unesp.br, avbenedetti@gmail.com (A.V. Benedetti).
}

literature (Bevilaqua et al., 2010; Monteiro et al., 1999; Sasaki et al., 1998). In the specific case of chalcopyrite $\left(\mathrm{CuFeS}_{2}\right)$, the most refractory and abundant copper source, it is understood that bacteria oxidize $\mathrm{Fe}^{2+}$ to $\mathrm{Fe}^{3+}$ ions, which attack the mineral sulfide (Bevilaqua et al., 2010). However, the refractory nature of this mineral sulfide prevents the achievement of high metal recoveries, and there is no agreement in the literature about the reasons for the slow dissolution rate of chalcopyrite (Crundwell, 2013; Holmes and Crundwell, 2013; Khoshkhoo et al., 2014a,b).

Recovery during the bioleaching process has been associated with the refractory properties of chalcopyrite and the formation of secondary surface species such as elemental sulfur, covellite (CuS), jarosites $\left(\mathrm{XFe}\left(\mathrm{SO}_{4}\right)_{2}(\mathrm{OH})_{6}\right.$, where $\mathrm{X}=\mathrm{K}^{+}, \mathrm{NH}_{4}^{+}, \mathrm{Na}^{+}$, or $\mathrm{H}_{3} \mathrm{O}^{+}$), copper polysulfide $\left(\mathrm{CuS}_{n}\right)$, and non-stoichiometric copper compounds. These are detrimental to the oxidation of the surface by microorganisms and, consequently, to the extraction of copper (Córdoba et al., 2008; Hackl et al., 1995; Li et al., 2013; Sasaki et al., 2009).

Among the strategies that can be used to overcome this limitation can be highlighted the prevention and/or modification of the 
surface layer formed during the oxidation process, by means of chemical or electrochemical control of the redox potential of the medium. Control of the redox potential of the $\mathrm{Fe}^{3+} / \mathrm{Fe}^{2+}$ pair can minimize the formation of iron precipitates, mainly by keeping the $\mathrm{Fe}^{3+} / \mathrm{Fe}^{2+}$ ratio low (Córdoba et al., 2008; Hiroyoshi et al., 2008a; Qin et al., 2013). There are many ways of controlling the potential, using the supply of oxygen (Third et al., 2002), addition of sodium sulfite (Sandström et al., 2005), use of chalcopyrite with a higher percentage of pyrite $\left(\mathrm{FeS}_{2}\right)$ (Hiroyoshi et al., 2008b), and imposition of potential by means of electrochemical techniques such as potentiostatic reduction (Nava et al., 2008), potential pulses (Lara et al., 2013), and cyclic voltammetry (Qin et al., 2013). Depending on the potential range imposed, different phases are formed on the surface, including bornite, covellite, elemental sulfur, non-stoichiometric copper compounds, and chalcocite (Ahmadi et al., 2011; Gu et al., 2013; Lara et al., 2013; Majuste et al., 2012; Nava et al., 2008). Generally, the imposed potential causes the reduction of chalcopyrite, which permits the extraction of iron from the crystalline structure, forming copper sulfides that are more susceptible to oxidative leaching (Gu et al., 2013). Additionally, the formation of jarosite under these conditions seems to be insufficient to block the surface, because these compounds are highly porous and are easily lost from the surface (Gu et al., 2013). Recently, Khoshkhoo et al. (2014a) studied a concentrated copper powder from the Boliden mine (Sweden), with application of a controlled redox potential, and concluded that a multicomponent surface layer consisting mainly of elemental sulfur and iron oxyhydroxides was responsible for hindering dissolution. Jarosite was eliminated from the list of possible substances that might be responsible for hindering chalcopyrite dissolution, and elemental sulfur was considered the main component of the obstructive layer. In other work, the only confirmed products resulting from the mineral oxidation were sulfur and jarosites (Klauber, 2008). Polysulfides do not passivate the chalcopyrite surface and the solids formed during the oxidation do not need to be electrical conductors to dissolve according to the electrochemical mechanism (Crundwell, 2013). The methodologies employed to identify the chalcopyrite surface layers and their implications have been criticized because of the absence of kinetic parameters (Crundwell, 2013).

In conclusion, electrochemical tests are important as alternatives for the study of bioleaching systems, because they enable assessment of the influence of ferric/ferrous ions on chalcopyrite, as well as evaluation of the possible influence of the redox potential in a medium that simulates the leaching conditions. These assays have the advantages of speed, convenience, relatively low cost, high sensitivity, low power consumption, and the use of small amounts of samples and reagents. In the specific case of electrochemical impedance spectroscopy, there is the additional advantage of being a transient technique in which the AC signal is applied to the system for only a short period, avoiding any detrimental effects on microorganisms. The oxidation of chalcopyrite by At. ferrooxidans has been studied using EIS techniques, including analysis of the correlation between changes in the mineral surface and bacterial adhesion (Bevilaqua et al., 2004), and the bioleaching of residues (Bevilaqua et al., 2013).

Considering that iron ions are ubiquitous in copper-based minerals such as chalcopyrite, the oxidant activity in bioleaching processes always leads to the formation of ferric ions and sulfuric acid (Bevilaqua et al., 2002). It was therefore decided to use EIS to compare the influence of redox potential on chalcopyrite dissolution, using different concentrations of ferrous ions and in the presence and absence of bacteria. A carbon paste electrode modified with chalcopyrite was utilized as the working electrode because of its advantages compared to massive electrodes. The latter tend to fracture during the polishing procedure and the resulting irregular and heterogeneous surface can affect the reliability of data recorded over the course of an experiment (Horta et al., 2009). The repeatability of this carbon paste electrode has already been proved in a previous study (Horta et al., 2009). The present work concerns the use of electrochemistry to study a system that simulates the main stages of chalcopyrite leaching and bioleaching in the presence of ferrous ions. The goal was to evaluate the ways in which the chemical potential imparted to the system by controlling the $\mathrm{Fe}^{2+}$ ions concentration could influence the electrochemical response.

\section{Electrochemical impedance spectroscopy}

When the applied perturbation is an AC potential and the response is an AC current, and vice versa, the transfer function is the impedance. Electrochemical impedance spectroscopy (EIS) is a method in which the impedance of an electrochemical system is measured as a function of the frequency of an applied AC wave. In this process, after the system has attained equilibrium or steady state, it is perturbed by applying an AC signal, so a new equilibrium or steady state is reached. The time (in seconds) taken for this relaxation is known as the time constant, $\tau$, which is given by:

$\tau=\mathrm{RC}$,

where $\mathrm{R}$ is the resistance (in ohms) and $\mathrm{C}$ is the capacitance (in farads). The time constant is characteristic of each event occurring in the system.

To simplify calculations, the perturbation and response are transformed from the time domain to the frequency domain using a Laplace transformation. In the frequency domain, fast processes (low $\tau$ values) occur at high frequencies, while slow processes (high $\tau$ values) occur at low frequencies. The frequency around which a process occurs may be ascertained using:

$\mathrm{F}=1 / 2 \pi \tau$

A great advantage of EIS is the wide frequency window normally employed $\left(10^{-3}\right.$ to $\left.10^{5} \mathrm{~Hz}\right)$, which enables investigation of all the processes occurring in this time domain. As a consequence, several time constants can be identified in the frequency range studied. Hence, solution resistance, porous layers, and barrier layers can be studied at high frequencies; intermediate frequencies can be used in the case of bulk properties, fast charge transfer processes, and oxide layer properties; and surface properties, slow charge transfer processes, and diffusion phenomena can be investigated at low frequencies. In simple terms, impedance may be considered as the 'resistance' to the flow of alternating current:

$\widetilde{E}=\widetilde{I} Z$,

where $\mathrm{E}$ and I are the waveform amplitudes for potential and current, respectively, and $\mathrm{Z}$ is the impedance. Two different components contribute to impedance: a real component due to the resistive response associated with resistors, generally represented by $Z_{\text {real }}$ or $Z^{\prime}$; and an imaginary component related to the capacitive or inductive response associated with capacitors, inducers, etc., represented by $-Z_{\text {imag }}$ or $-Z^{\prime \prime}$.

The impedance $Z$ is a complex quantity that depends on the frequency ( $\omega=2 \pi \mathrm{f}$, where $\omega$ is given in radians and $\mathrm{f}$ in $\mathrm{Hz}$ ), and for each frequency it is only possible to measure one impedance value, except in the case of a pure resistor where $Z(\omega)=R$, a point on the $Z_{\text {real }}$ axis of the Nyquist plot. The impedance in Cartesian coordinates is given by:

$Z(\omega)=Z_{\text {real }}(\omega)-j Z_{\text {imag }}(\omega)$,

where $\mathrm{j}$ is a complex number and $\mathrm{j}^{2}=-1$. 
If $-Z_{i m a g}$, on the $y$-axis, is plotted against $Z_{\text {real }}$, on the $x$-axis, the complex plane (Nyquist) graph is obtained. The modulus of impedance, $|\mathrm{Z}|$, is given by:

$|Z|^{2}=\left(Z_{\text {real }}\right)^{2}+\left(Z_{\text {imag }}\right)^{2}$,

and the phase angle, $\phi$, is given by:

$\phi=\tan ^{-1}\left(Z_{\text {imag }} / Z_{\text {real }}\right)$.

The impedance data can then also be presented as Bode plots: log $|\mathrm{Z}|$ vs. $\log \mathrm{f}$, and $-\phi$ (degrees) vs. $\log \mathrm{f}$.

The Nyquist and Bode plots for a simulated simple charge transfer process (only one time constant) occurring at an electrode/solution interface are shown in Fig. 1.

The main parameters that can be directly obtained from the Nyquist plot for a simple electrochemical process are the solution resistance $\left(R_{s}\right)$, the polarization resistance $\left(R_{p}\right)$, and the charge transfer resistance $\left(R_{C T}\right)$. A simple charge transfer process produces only one semicircle, with a maximum at the characteristic frequency $\left(\omega_{\mathrm{ch}}=1 / \mathrm{RC}=1 / \tau\right)$. An EIS diagram with two or more separate semicircles indicates the presence of two or more time constants. If the time constants are not well defined, the semicircles can be overlapped to varying degrees.

A phase angle plot that is completely symmetric with respect to the maximum (characteristic frequency), together with the presence of two or more peaks, is indicative of the existence of at least two or more time constants (electrode processes). If the time constants have closely similar values, the phase angle plot may show only one asymmetric peak. These features are also observed in the modulus of impedance plots: for only one time constant, a straight line with slope -1 is observed, while two or more straight lines indicate at least two or more time constants. It is difficult to distinguish two overlapped time constants in the modulus of impedance plots.

When semi-infinite linear diffusion is present, a more complex Nyquist plot is obtained (Fig. 2) and the corresponding time constant is generally observed in the low frequency region (the Warburg impedance).

The presence of semi-infinite linear diffusion produces a straight line with slope of -45 degrees in the low frequency region of the Nyquist plot, and a continuous increase in the $\log |\mathrm{Z}| v s . \log \mathrm{f}$ plot. More details about electrochemical impedance can be found in several textbooks.

\section{Experimental}

\subsection{Starting material}

The chalcopyrite $\left(\mathrm{CuFeS}_{2}\right)$ used in the tests was a natural material from La Chorrera city in the county of Cisneros (Antioquia, Colombia). The mineral was ground and sieved to $100 \%<115$ mesh (125 $\mu \mathrm{m}$ sieve). Atomic absorption analysis revealed that the metal contents were $30.86 \% \mathrm{Cu}$ and $24.4 \% \mathrm{Fe}$.

\subsection{Electrolyte, electrodes, and electrochemical cell}

\subsubsection{Electrolyte}

In all the electrochemical studies, the electrolyte used was an aqueous solution containing $0.5 \mathrm{~g} / \mathrm{L}$ of each of the salts $\left(\mathrm{NH}_{4}\right)_{2} \mathrm{SO}_{4}$, $\mathrm{K}_{2} \mathrm{HPO}_{4}$, and $\mathrm{MgSO}_{4} \cdot 7 \mathrm{H}_{2} \mathrm{O}$, at $\mathrm{pH} 1.8$ (adjusted with concentrated $\mathrm{H}_{2} \mathrm{SO}_{4}$ ), herein named solution A (Tuovinen and Kelly, 1973).

\subsubsection{Electrodes}

Carbon paste electrodes were prepared with and without chalcopyrite. The constituents of the carbon paste working electrodes were: graphite powder $(<20 \mu \mathrm{m}$, Alfa Aeser), Nujol mineral oil, and chalcopyrite $(50 \mathrm{wt} . \%$, particle size $\sim 37 \mu \mathrm{m}$ ) (Horta et al., 2009). Chloroform was used to homogenize the carbon pastes and was volatilized after a few minutes. After preparation, the paste was packed into a cavity ( $3 \mathrm{~mm}$ diameter, $0.07 \mathrm{~cm}^{2}$ area) in the body of a Teflon rod, forming the working electrode, in an assembly similar to that described previously (Ferreira et al., 2011). The experiments were performed under stirred conditions, employing a rotating disk system (Model AFMSRX, Pine Instruments) with an interchangeable disk electrode. The carbon paste electrode was suitably fitted in the rotating disk system. A platinum mesh was used as the auxiliary electrode, and the reference electrode was $\mathrm{Ag}|\mathrm{AgCl}| \mathrm{KCl}_{\text {sat }}(+0.197 \mathrm{~V} / \mathrm{SHE})$. All potential values were referred to the $\mathrm{Ag} \mid \mathrm{AgCl}$ electrode.

\subsubsection{Electrochemical cell}

A conventional three-electrode electrochemical cell was used for the open circuit potential $\left(E_{\mathrm{OC}}\right)$ and EIS measurements. The working electrode was positioned vertically and fixed on the top of the electrochemical cell. The reference electrode was connected to a platinum disk through a $0.1 \mu \mathrm{F}$ non-electrolytic capacitor to prevent phase shift at high frequency. Prior to use, the electrochemical cell and electrodes were left in concentrated sulfuric acid for at least $40 \mathrm{~min}$ and were then rinsed thoroughly with water obtained from a Milli-Q system (Millipore).

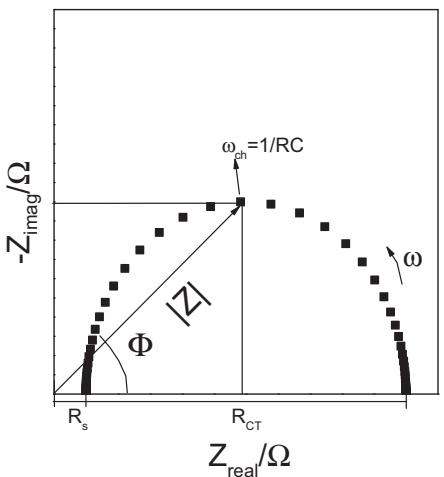

(a)



(b)

Fig. 1. Nyquist (a) and Bode (b) plots. 


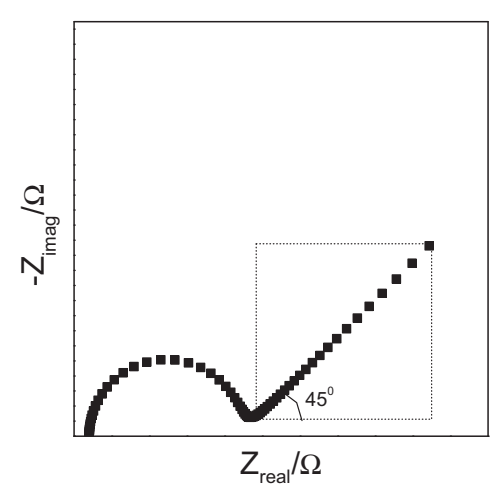

(a)

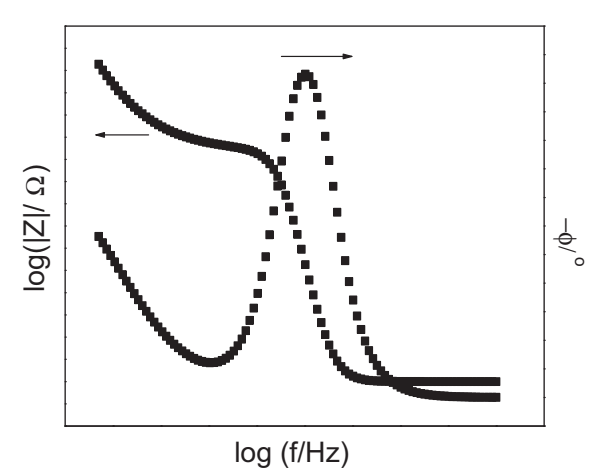

(b)

Fig. 2. Nyquist (a) and Bode (b) plots in the presence of semi-infinite linear diffusion.

\subsection{Bacterial strain}

The strain used was At. ferrooxidans LR, isolated from an acid leachate of uranium mineral from Lagoa Real in Bahia State, Brazil (Garcia Jr, 1991).

\subsection{Cell suspension}

The $10^{8}$ cells/mL suspensions employed in the EIS tests were obtained using the T\&K culture medium composed of solutions $\mathrm{A}$ (described above) and $\mathrm{B}\left(33.3 \mathrm{~g} / \mathrm{L} \mathrm{FeSO}_{4} \cdot 7 \mathrm{H}_{2} \mathrm{O}\right)$, both at $\mathrm{pH} 1.8$, adjusted with concentrated $\mathrm{H}_{2} \mathrm{SO}_{4}$ (Tuovinen and Kelly, 1973). Solution A was sterilized by autoclaving $\left(120^{\circ} \mathrm{C}, 20 \mathrm{~min}, 1 \mathrm{~atm}\right)$, and solution $\mathrm{B}$ was filtered using a previously autoclaved system containing a cellulose ester membrane filter $(0.45 \mu \mathrm{m}$ pore diameter, Millipore HAWP 04700). Prior to use, solutions A and B were mixed in a proportion of $4: 1$. The cells used for the electrochemical analysis were obtained after growth for $48 \mathrm{~h}$ in a shaker (150 rpm, $30^{\circ} \mathrm{C}$ ), with successive washing and centrifugation (5000g) to eliminate residual ferric ions from the medium. The washed suspension was further centrifuged at $12,000 \mathrm{~g}$ for $25 \mathrm{~min}$, washed twice in Milli-Q water $(18 \mathrm{M} \Omega \mathrm{cm})$, and finally suspended in $10 \mathrm{~mL}$ of solution $\mathrm{A}$ of the T\&K culture medium, using analytical grade chemicals and Milli-Q water. This procedure removed the exopolymeric substances (EPS) from the cellular envelope (Gehrke et al., 1998). Hence, the bacterial suspensions used in the electrochemical studies did not initially contain any EPS. The cell suspension was standardized using absorption measurements (Barron and Lueking, 1990).

\subsection{Electrochemical studies}

Before use, solution A and the iron-containing solution were sterilized as described in Section 3.4. Firstly, electrochemical studies were conducted using an electrode without the sulfide mineral in order to evaluate the behavior of the carbon paste electrode in solution $A$ in the absence or presence of ferrous ions (at concentrations of 0.10 and $0.30 \mathrm{~mol} \mathrm{~L}^{-1}$ ). Electrochemical measurements were then performed using the carbon paste electrode modified with chalcopyrite, in the absence or presence of ferrous ions and At. ferrooxidans. These concentrations were used because the salt solution employed for bacterial growth contained $0.12 \mathrm{~mol} \mathrm{~L}^{-1}$ $\mathrm{Fe}^{2+}$, while $\mathrm{Fe}^{2+}$ ion concentrations of up to $0.3 \mathrm{~mol} \mathrm{~L}^{-1}$ were used in the shake flask experiments.

The open circuit potential $\left(E_{O C}\right)$ was measured before and after each EIS measurement, and the potential values read before the measurements were plotted against time; no significant differences were observed for $\mathrm{E}_{\mathrm{OC}}$ values obtained before and after each EIS analysis. EIS diagrams were obtained in the frequency range from $10^{5}$ to $5 \times 10^{-3} \mathrm{~Hz}$, applying an AC potential amplitude of $10 \mathrm{mV}$ rms on the $E_{O C}$ and recording 10 points per frequency decade. The measurements were performed with a Gamry Instruments potentiostat (Model FAS2 Femtostat). Sequential EIS measurements were performed for $97 \mathrm{~h}$, and for each condition the EIS measurement was only started after the $\mathrm{E}_{\mathrm{OC}}$ had stabilized. The impedance of a carbon paste electrode modified with chalcopyrite was at least 50 -fold lower than that of an unmodified electrode, so the impedance measured was dominated by the modifying component. The Lissajous figures were observed in real time using the Gamry system, and no distortions were detected. All the electrochemical measurements were performed using unstirred or stirred and naturally aerated solutions. Additionally, EIS measurements were performed at the $\mathrm{E}_{\mathrm{OC}}$, but using the rotating disk electrode of carbon paste modified with chalcopyrite at $1500 \mathrm{rpm}$ in the non-inoculated systems during the EIS measurements. Quantitative analyses of the EIS data will be presented in a future paper, due to the complexity of the modeling and to avoid greatly extending the present article. All the electrochemical experiments were performed at $25^{\circ} \mathrm{C}$.

\subsection{Bioleaching and chemical leaching}

All the bioleaching tests were performed using an orbital shaker at $150 \mathrm{rpm}$ and $30^{\circ} \mathrm{C}$, with Erlenmeyer flasks containing mineral salts medium (Tuovinen and Kelly, 1973) at pH 1.80 plus ferrous sulfate as energy source at different concentrations $(0,0.10,0.20$, and $\left.0.30 \mathrm{~mol} \mathrm{~L}^{-1}\right), 2.5 \%(\mathrm{w} / \mathrm{v})$ of chalcopyrite sample, and $5.0 \%$ (v/v) of At. ferrooxidans LR. Abiotic conditions were also employed. The experiments were carried out in duplicate, with a final volume of $150 \mathrm{~mL}$. Compensation for evaporation was achieved by adding sterile distilled water. Aliquots of the slurries in the vials were removed at the end of bioleaching tests, for analysis of the solid phase. The starting material and the solid residues were analyzed by X-ray diffraction (XRD) using a Siemens D5000 diffractometer. The surfaces of the chalcopyrite and the leaching assay residues were examined by EDS coupled to scanning electron microscopy (SEM), using a JEOL JSM-7500F field emission electron microscope (FEG) and a NORAN System 6 energy dispersive X-ray spectrometer (EDS). The leaching and bioleaching assays were conducted at $30^{\circ} \mathrm{C}$.

\section{Results and discussion}

\subsection{Starting material characterization}

The chalcopyrite morphology and the particle size distribution of the starting material used to prepare the carbon paste electrodes are illustrated in Fig. 3. 
Analysis of the chalcopyrite powder surface by EDS revealed the presence of copper, iron, sulfur, and oxygen. The detection of oxygen in the chalcopyrite powder, at around $8 \mathrm{wt} . \%$, indicated the presence of a metallic oxide-based layer on the surfaces of the particles. According to a recent review (Li et al., 2013), the film present on the chalcopyrite surface could be composed of iron oxides/ hydroxides $\left(\mathrm{Fe}_{2} \mathrm{O}_{3}\right.$ and $\left.\mathrm{FeOOH}\right), \mathrm{Cu}_{2} \mathrm{O}, \mathrm{Cu}_{2} \mathrm{~S}$, and possibly sulfates (depending on the time of oxidation in air). In the same review, it was also reported that these kinds of layers are present at thicknesses in the range from 1.2 to $40 \mathrm{~nm}$, and that they may slowly undergo further oxidation or even subsequent aqueous leaching. However, the X-ray diffractograms (Fig. 4) only revealed the presence of a sulfide phase in the chalcopyrite. No metals other than copper and iron were detected. Therefore, the results obtained here indicated the presence of a thin oxide layer that was undetectable by XRD under the conditions employed, and the presence of the chalcopyrite phase alone.

\subsection{Electrochemical studies}

Although the $\mathrm{E}_{\mathrm{OC}}$ was found to become stabilized following $12 \mathrm{~h}$ of immersion in all the systems studied, the data shown consider the results for the period from $14 \mathrm{~h}$ to $97 \mathrm{~h}$ of immersion, since for most of the systems studied there were no significant differences in the EIS diagrams obtained after longer times.

Firstly, a study of different concentrations of ferrous ions in solution A was performed with the carbon paste electrode (control experiment), to enable comparisons with more complex systems. EIS diagrams recorded at $\mathrm{E}_{\mathrm{OC}}(0.42 \mathrm{~V})$ for the carbon paste electrode in contact with solution A were found to display a single

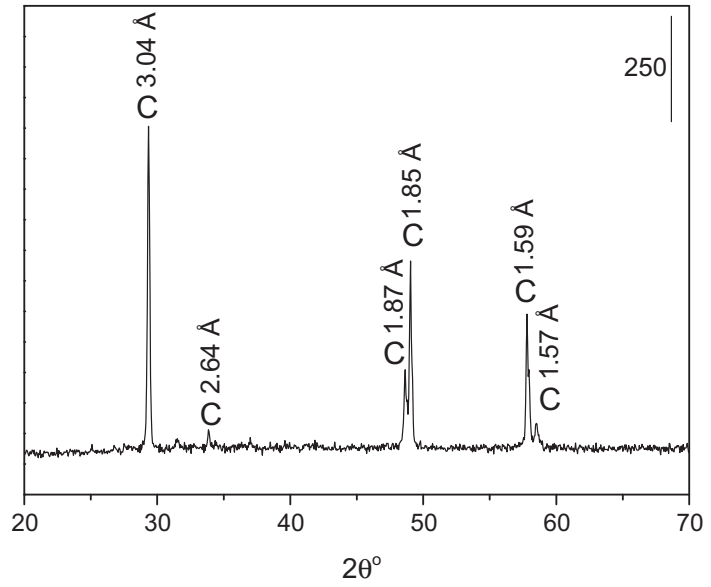

Fig. 4. X-ray diffractogram of the chalcopyrite starting material. C: chalcopyrite; lateral bar: peak intensity; numbers above the peaks show the interplanar distance (d, in $\AA$ ) of each crystalline phase.

and slightly flattened semicircle, with a high polarization resistance $(\geqslant 5 \mathrm{M} \Omega$ ), which was in agreement with the expected quasi-ideal polarizable behavior of graphite particles in such a solution, and was much higher than the impedance values measured for all the other systems studied here.

\subsubsection{Carbon paste electrode in the presence of $\mathrm{Fe}^{2+}$ ions}

EIS measurements were then performed with the carbon paste electrode immersed in solution A containing 0.10 or $0.30 \mathrm{~mol} \mathrm{~L}^{-1}$

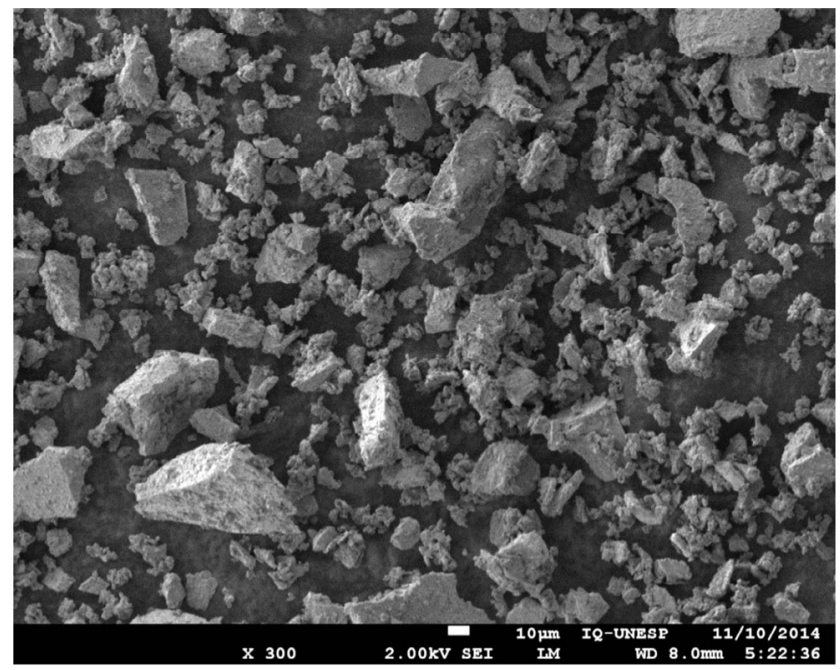

(a)

CAL-05(1)
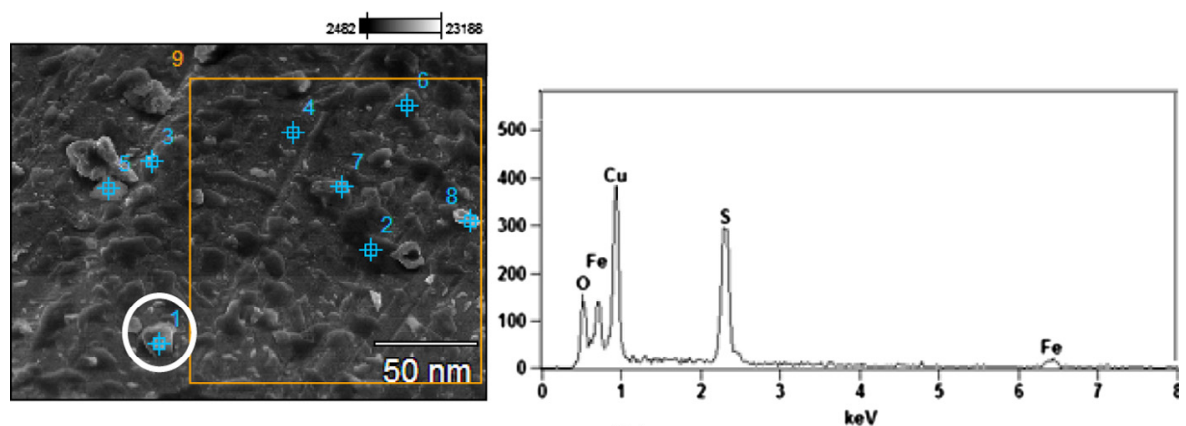

(b)

Fig. 3. (a) SEM micrograph of chalcopyrite powder; (b) highlight of one of the surface regions and EDS spectrum of the surface of particle \#1. 
ferrous ions, in order to evaluate the response of this electrode in the presence of ferrous ions without chalcopyrite. EIS diagrams obtained after $97 \mathrm{~h}$ for the assays with solution A containing 0.10 or $0.30 \mathrm{~mol} \mathrm{~L}^{-1}$ iron(II) are shown in Figs. 5 and 6, respectively. The presence of ferrous ions in the solution led to a considerable decrease in the impedance response, compared to the carbon paste electrode, with the decrease being more pronounced at the higher concentration of ferrous ions.

The evolution of the $\mathrm{E}_{\mathrm{OC}}$ measured prior to the beginning of each electrochemical impedance experiment is shown in the inserts of Figs. $5 \mathrm{~A}$ and $6 \mathrm{~A}$. It is noteworthy that for the first $67 \mathrm{~h}$ of immersion in solution A containing $0.10 \mathrm{~mol} \mathrm{~L}^{-1} \mathrm{Fe}^{2+}$ ions, there was an almost linear small increase (from 0.27 to $0.29 \mathrm{~V}$ ), with a low slope $\left(0.33 \mathrm{mV} \mathrm{h}^{-1}\right)$ that was constant until the end of the period (insert of Fig. 5A). At $\mathrm{E}_{\mathrm{OC}}$, parallel reduction and oxidation reactions occurred simultaneously. In an acidic solution containing $\mathrm{Fe}^{2+}$ ions, such reactions can be attributed to oxygen reduction and iron (II) oxidation. Slight turbidity of the solution was observed at long immersion times, although precipitates were not observed in the bottom of the cell, even after $97 \mathrm{~h}$ of the experiment. The results could be qualitatively explained based on the chemical behavior of the salts solution containing ferrous ions. The slight increase in the $\mathrm{E}_{\mathrm{OC}}$ (inset of Fig. $5 \mathrm{~A}$ ) could be explained by the slow oxidation of $\mathrm{Fe}^{2+}$ to $\mathrm{Fe}^{3+}$ by oxygen, as has been observed in air (Baes Jr. and Mesmer, 1976). The oxidation of ferrous ions by oxygen occurs according to Eq. (1):

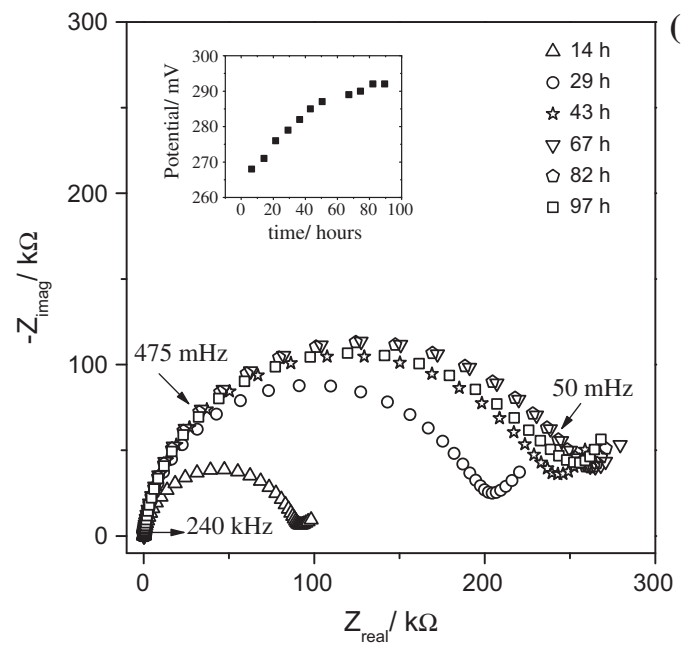

(A)

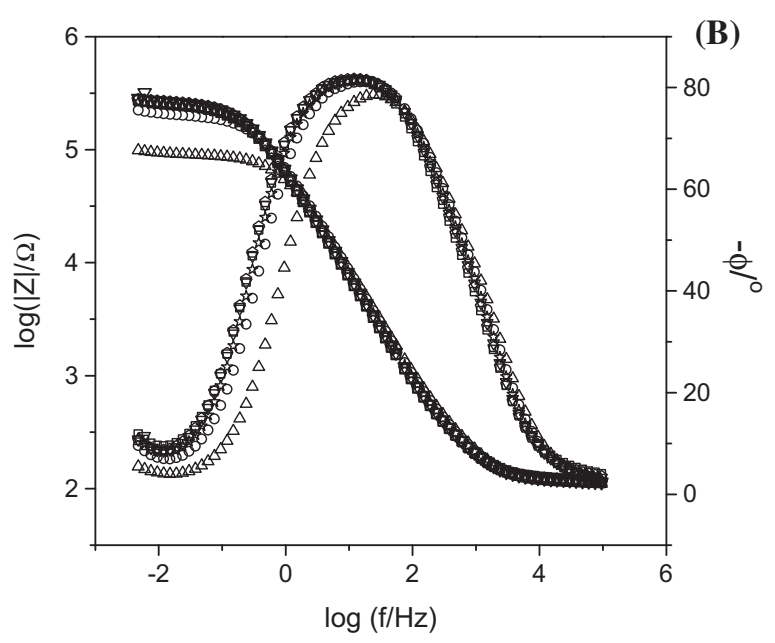

Fig. 5. (A) Experimental complex plane and (B) Bode plots for carbon paste electrodes in aerated and unstirred solution A containing $0.10 \mathrm{~mol} \mathrm{~L}^{-1}$ ferrous ions, recorded for $97 \mathrm{~h}$. Inset in $(\mathrm{A})$ : Open circuit potential vs. time.

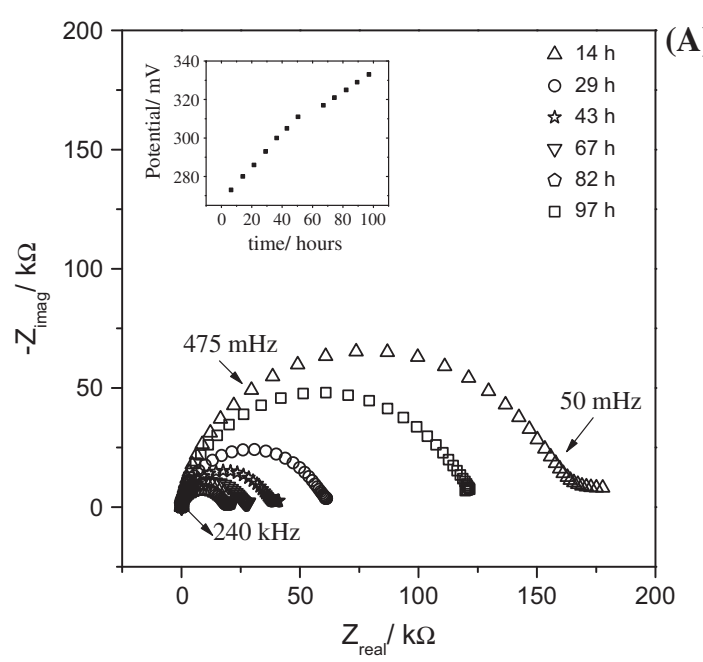

(A)

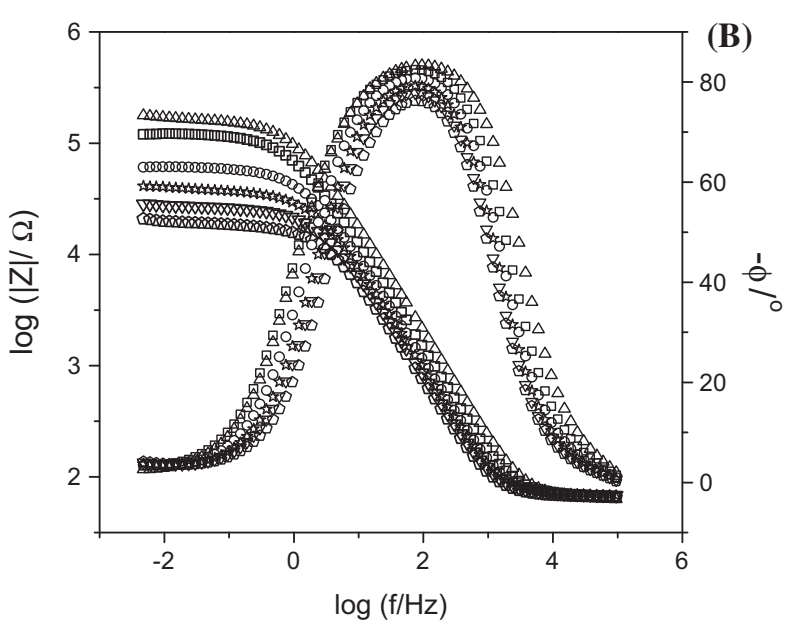

Fig. 6. (A) Experimental complex plane and (B) Bode modulus and phase angle plots for carbon paste electrodes in natural aerated salts solution with the addition of $0.30 \mathrm{~mol} \mathrm{~L}^{-1}$ ferrous ions, recorded for $97 \mathrm{~h}$. Inset in (A): Open circuit potential $v$ s. time.

$2 \mathrm{Fe}^{2+}+2 \mathrm{H}^{+}+1 / 2 \mathrm{O}_{2} \rightarrow 2 \mathrm{Fe}^{3+}+\mathrm{H}_{2} \mathrm{O}$

Kinetic studies of this reaction have led to different activation energies and rate laws, with values of the reaction order from -0.25 to -0.35 , with respect to the proton (Verbaan and Crundwell, 1986). Until recently, the steps of the mechanism were not explicitly described (Crundwell, 2013).

This reaction acts to increase the $\mathrm{pH}$ of the solution by removing protons from the medium. Here, the use of an unstirred solution resulted in ferrous ions oxidation being strongly dependent on the diffusion of oxygen (Baes Jr. and Mesmer, 1976). The fact that the solution $\mathrm{pH}$ was not corrected during our experiment led to hydrolysis of the ferric ions. The hydrolysis of $\mathrm{Fe}^{3+}$ ions begins at about $\mathrm{pH} 1$, with the formation of different charged species in the acidic medium, depending on the nature and concentration of the anions, temperature, rate of oxygenation, and so on (Gotic and Music, 2007; Khoe and Robins, 1988; Parida and Das, 1996a, b). These studies indicated that the oxide/hydroxide formed is extremely dependent on experimental conditions. The $\mathrm{SO}_{4}^{2-} / \mathrm{Fe}^{3+}$ molar ratio determines the types of oxides and their structure and properties: goethite is produced at $\mathrm{SO}_{4}^{2-} / \mathrm{Fe}^{3+} \leqslant 0.5$, while $\mathrm{SO}_{4}^{2-} / \mathrm{Fe}^{3+} \geqslant 1$ results in formation of the $\mathrm{FeSO}_{4}^{+}$complex and the polymerization of hydroxy complexes, with decreased precipitation of goethite. Therefore, for ratios $\geqslant 1$, generation of the $\mathrm{FeSO}_{4}^{+}$ complex becomes extremely important for the formation of 
compounds such as iron hydroxysulfate. The aqueous solution containing the products of partial or complete hydrolysis of $\mathrm{Fe}^{3+}$ ions has a colloidal character. The chemical process proceeds with formation of a gel-like material and/or precipitates, depending on the $\mathrm{Fe}^{2+}$ ions concentration, leading to the expected production of iron oxide, hydroxide, and sulfate species. Precipitates were not observed when the electrode was used in $0.1 \mathrm{~mol} \mathrm{~L}^{-1}$ ferrous ions solution.

Fig. 5A also shows complex plane plots with a large capacitive semicircle followed by a diffusional component at low frequencies. The size of the semicircle increased with immersion time up to $82 \mathrm{~h}$, especially from 14 to $29 \mathrm{~h}$, and there was a slight decrease between 82 and $97 \mathrm{~h}$. At low frequencies, the impedance modulus plots (Fig. 5B) followed the same trend observed for the complex plane plots. The plots of Bode phase angle against log $\mathrm{f}$ (Fig $5 \mathrm{~B}$ ) showed a broad phase angle in the medium frequency region and a diffusion feature in the low frequency region (see Section 2). The phase angle showed a small increase and a slight shift to lower frequency values between 14 and $29 \mathrm{~h}$ of immersion, and then remained almost constant until the end of the experiment.

The small enlargement of the semicircle in the complex plane plots, as well as the increase of impedance modulus at low frequencies, were related to changes at the electrode/solution interface. The observation of a degree of turbidity at the end of the experiment was indicative of the occurrence of surface changes, even at short immersion times, with evolution to a gel-like material and consequent modification of the impedance response.

Fig. 6 shows the EIS diagrams recorded with addition of $0.30 \mathrm{~mol} \mathrm{~L}^{-1} \mathrm{Fe}^{2+}$ ions to the salts solution.

The inset in Fig. $6 \mathrm{~A}$ shows that the $\mathrm{E}_{\mathrm{OC}}$ increased at $\sim 0.9 \mathrm{mV} \mathrm{h}^{-1}$ up to $50 \mathrm{~h}$ of immersion, and at $0.5 \mathrm{mV} \mathrm{h}^{-1}$ for longer immersion times, with a total increase of $\sim 70 \mathrm{mV}$. This increase was considered to be a consequence of the continuous chemical oxidation of $\mathrm{Fe}^{2+}$ to $\mathrm{Fe}^{3+}$ by oxygen, as mentioned previously, resulting in a precipitate over the entire electrode surface. A typical color corresponding to the presence of iron(III) ions in solution was observed with increasing immersion time.

The impedance followed an inverse trend, compared to the EIS diagrams shown in Fig. 5, with the size of the capacitive semicircles only decreasing with immersion time, while the semi-infinite linear diffusion feature at low frequency was not evident. The real impedance values were lower than measured for the salts solution containing $0.10 \mathrm{~mol} \mathrm{~L}^{-1} \mathrm{Fe}^{2+}$ ions. At low frequencies (LF), the impedance modulus values were also found to decrease with immersion time (Fig. 6B). The increase in the ferrous ions concentration, and consequently the increase in ferric ions, was responsible for a corresponding decrease over time of the semicircle and impedance modulus at low frequencies. This was associated with the formation of charged ions such as $\mathrm{FeSO}_{4}^{+}$, a gel-like material, and then precipitates on the electrode surface. The Bode phase plots apparently showed one time constant, but the plots were asymmetric, indicating the existence of more than one time constant (see Section 2). The phase angle decreased from $-83^{\circ}$ to $-76^{\circ}$, and the frequency at the maximum remained practically constant. The width at half-height of the peak (frequency interval) decreased with the immersion time, with values of $3775-0.96 \mathrm{~Hz}$ at $14 \mathrm{~h}$ and $1500-3 \mathrm{~Hz}$ at $97 \mathrm{~h}$, suggesting that the two time constants overlapped each other.

Turbidity of the solutions was observed from the beginning of the experiments, different to the behavior seen using the more dilute $\mathrm{Fe}^{2+}$ solution. The general explanation for the chemical behavior of $0.30 \mathrm{~mol} \mathrm{~L}^{-1} \mathrm{Fe}^{2+}$ ions in solution was essentially the same as for solution A with $0.10 \mathrm{~mol} \mathrm{~L}^{-1} \mathrm{Fe}^{2+}$. It was assumed that an increase in the ferrous ions concentration in solution promoted the initial formation of more ferric ions, hence causing an accumulation of products from the $\mathrm{Fe}^{3+}$ hydrolysis, leading to the precipitation of iron oxyhydroxide on the electrode surface, since the active species in solution were iron and oxygen $/ \mathrm{H}^{+}$. The hydrolysis of $\mathrm{Fe}^{3+}$ ions begins at about $\mathrm{pH} 1$, with the formation of iron oxides/hydroxides containing more or fewer sulfate ions and some water of hydration, followed by the precipitation of different structures of $\mathrm{FeSO}_{4}^{+}$and $\mathrm{FeO}(\mathrm{OH})$, which could be hydrated. The formation of iron oxyhydroxide-sulfate and dissolved species is dynamic and the electrical properties of the layer can change with the immersion time, as observed in the EIS diagrams (Fig. 6). The EIS diagrams did not allow separation of the effects of the iron oxyhydroxide-sulfate layer and the charge transfer process occurring on the electrode surface, suggesting that this layer was conductive and porous. Further studies will be needed in order to know whether the charge transfer process mainly involves ferric or ferrous ions from the bulk solution and/or from the iron oxide/hydroxide-sulfate layer.

The precipitation of gel-like Fe in ferrous solution was therefore probably in the form of jarosite or hydroxy-sulfate iron(III) salt. A gel-like material was clearly observed using $0.3 \mathrm{~mol} \mathrm{~L}^{-1}$ ferrous ions, but the small amount of precipitated material obtained from the electrode surface (unmodified carbon paste with a small area) was not sufficient for analysis of its composition. A gel-like material was also observed at the end (after $96 \mathrm{~h}$ ) of the experiment with $0.1 \mathrm{~mol} \mathrm{~L}^{-1}$ ferrous ions. For this reason, it was difficult to define the chemical nature of the precipitated Fe.

\subsubsection{Chalcopyrite-modified carbon paste electrode in the absence and presence of $\mathrm{Fe}^{2+}$ ions}

Fig. 7 shows the EIS spectra recorded for the chalcopyritemodified carbon paste electrode, and the inset in Fig. 7A shows the evolution of the $\mathrm{E}_{\mathrm{OC}}$ during the almost $100 \mathrm{~h}$ of the experiment. In the first $50 \mathrm{~h}$, the potential showed an almost linear decrease of $12 \mathrm{mV}$ (from 280 to $268 \mathrm{mV}$ ), while an increase of $43 \mathrm{mV}$ (from 268 to $311 \mathrm{mV}$ ) was observed in the subsequent $50 \mathrm{~h}$. The first decrease could be attributed to the partial or total removal of metallic (mainly iron) oxides from the chalcopyrite surface by the acid solution, considering that the chalcopyrite surface contained metallic oxides (as described above). The ferric ions released from the surface increased their concentration near the electrode surface, hence enabling the increase of the potential for longer immersion times. Once formed, the iron(II) ions could be oxidized by oxygen, but the amount of ferric ions released was unlikely to be sufficient to produce a significant iron oxyhydroxide layer, as, for instance, obtained using solution A with $0.3 \mathrm{~mol} \mathrm{~L}^{-1} \mathrm{Fe}^{2+}$ ions. Therefore, the chalcopyrite surface modification can be understood as changes caused by the partial or total dissolution of native metallic oxides, with slow release of copper and iron from the mineral, resulting in a new surface composed of secondary phases and/or metal-deficient polysulfides (Bevilaqua et al., 2004, 2013). Recently, Zhao et al. (2015) demonstrated that chalcopyrite could be reduced at $\mathrm{E}<\sim 0.3 \mathrm{~V}$ and oxidized at $\mathrm{E}>\sim 0.3 \mathrm{~V} / \mathrm{Ag}|\mathrm{AgCl}| \mathrm{KCl}_{\text {sat }}$, and that polysulfide could be formed by direct oxidation of chalcopyrite.

The impedance response of chalcopyrite changed completely between 43 and $67 \mathrm{~h}$ of immersion (Fig. 7), and the size of the semicircles mainly decreased during this period (Fig. 7A). For $\mathrm{t}>43 \mathrm{~h}$, a smaller semicircle in the medium frequency region was observed, followed by a feature that resembled a diffusion component at low frequency.

The Bode phase angle plots (Fig. 7B) depicted at least two time constants for all the impedance diagrams, with the one at low frequencies being related to different processes, depending on the immersion time. A peak with a phase angle close to $-60^{\circ}$ was observed at around $100 \mathrm{~Hz}$, and remained almost constant throughout the period of the experiment. At frequencies below $1 \mathrm{~Hz}$, the second time constant changed, suggesting more complex 


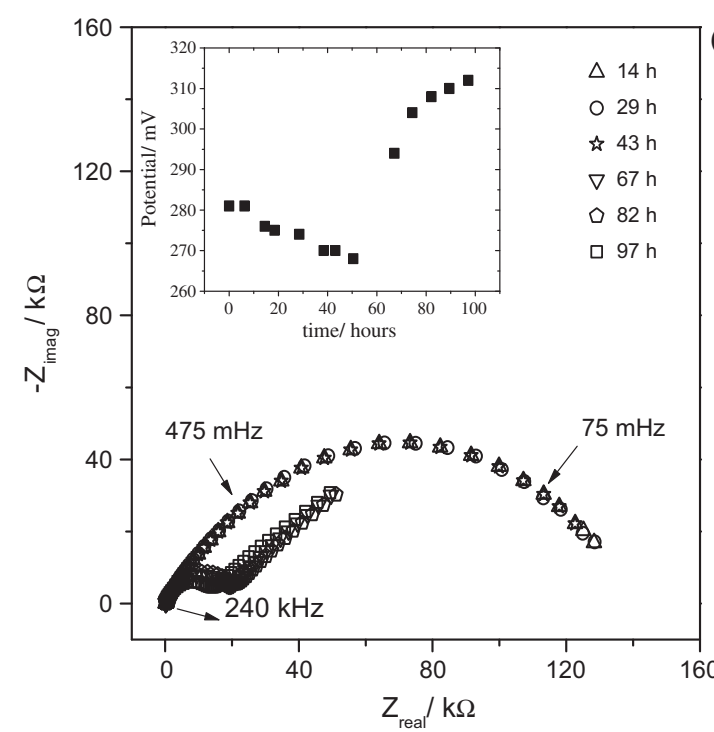

(A)

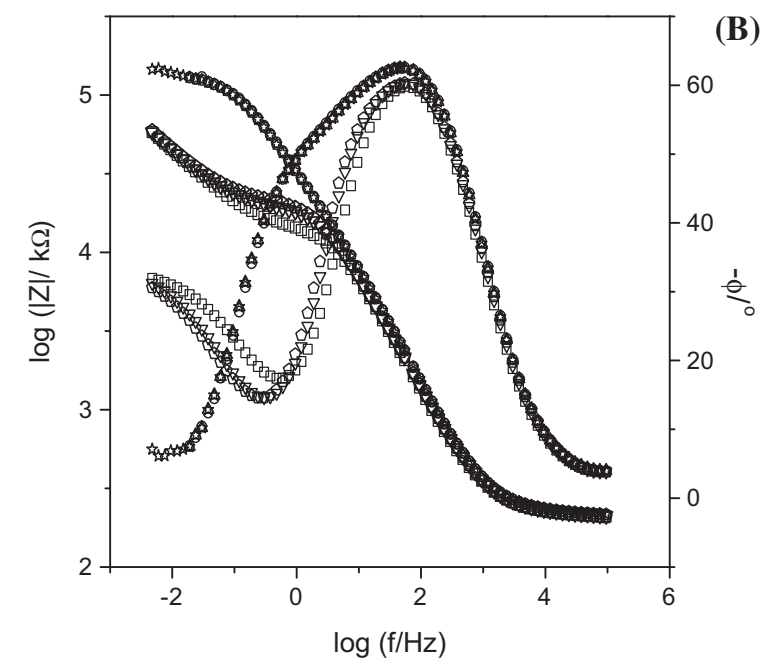

Fig. 7. (A) Experimental complex plane and (B) Bode modulus and phase angle plots for carbon paste electrodes modified with chalcopyrite in aerated solution $A$, recorded for $97 \mathrm{~h}$. Inset in (A): Open circuit potential vs. time.

behavior, followed by a diffusion feature after $43 \mathrm{~h}$ of immersion, which was clearly observed in the modulus of impedance (with a continuous increase in the $|\mathrm{Z}|$ values; see Section 2).

The time constant in the higher frequency region was attributed to the charge transfer processes occurring at the chalcopyrite/solution interface, because it was always present and was related to the chalcopyrite oxidation/reduction and oxygen $/ \mathrm{H}^{+}$reduction reactions. The second time constant (LF), for $t \leqslant 43 \mathrm{~h}$, was related to the presence of a native metallic oxide-based layer on the chalcopyrite surface, as demonstrated previously, which partially or totally dissolved with time in the acid solution. The influence of this layer was dependent on the initial state of the chalcopyrite particle surface, the composition of the solution, and the exposure time. This layer became less significant after $43 \mathrm{~h}$ of immersion in solution $\mathrm{A}$, but the impedance of the system continued to increase with time, suggesting the deposition/formation of a new layer. Therefore, a parallel experiment (not shown) was performed: a chalcopyrite-modified carbon paste electrode was rotated at $1500 \mathrm{rpm}$ in solution A. Under these conditions, precipitates of iron oxyhydroxide (iron was not added to this solution) could not become attached to the electrode surface, but the capacitive semicircle increased with time, indicating that the partial dissolution of chalcopyrite led to the formation of a new and more resistive layer, which was probably a non-stoichiometric metal-deficient sulfurenriched layer (Li et al., 2013), as already mentioned. However, no passivation of the chalcopyrite surface was observed.

Fig. 8 shows the EIS diagrams obtained with the carbon paste electrode modified with chalcopyrite and immersed in solution $\mathrm{A}$ containing $0.10 \mathrm{~mol} \mathrm{~L}^{-1}$ ferrous ions in the absence of bacteria. The inset in Fig. 8A shows that the potential values increased linearly with immersion time. This system was more complex due to the presence of iron(II), since the $\mathrm{Fe}^{3+} / \mathrm{Fe}^{2+}$ reaction could theoretically occur on both the graphite and the chalcopyrite particles. The assays performed with the carbon paste-graphite electrode and iron(II) (Fig. 5) showed a much higher resistance, compared to the assays using the carbon paste-graphite electrode modified with chalcopyrite (Fig. 7). Moreover, the carbon paste contained a proportion of chalcopyrite, favoring the occurrence of reactions with (and on) the mineral sulfide. However, further studies will be needed in order to know if chalcopyrite dissolution and ferrous ions oxidation can be observed separately in EIS diagrams obtained using carbon paste electrodes.

The complex plane plots (Fig. 8A) showed two capacitive semicircles for immersion times up to around $29 \mathrm{~h}$, after which the semicircles seemed to evolve to a single capacitive semicircle, followed by a diffusion contribution for longer times. The real measured impedance was higher than obtained under the conditions of
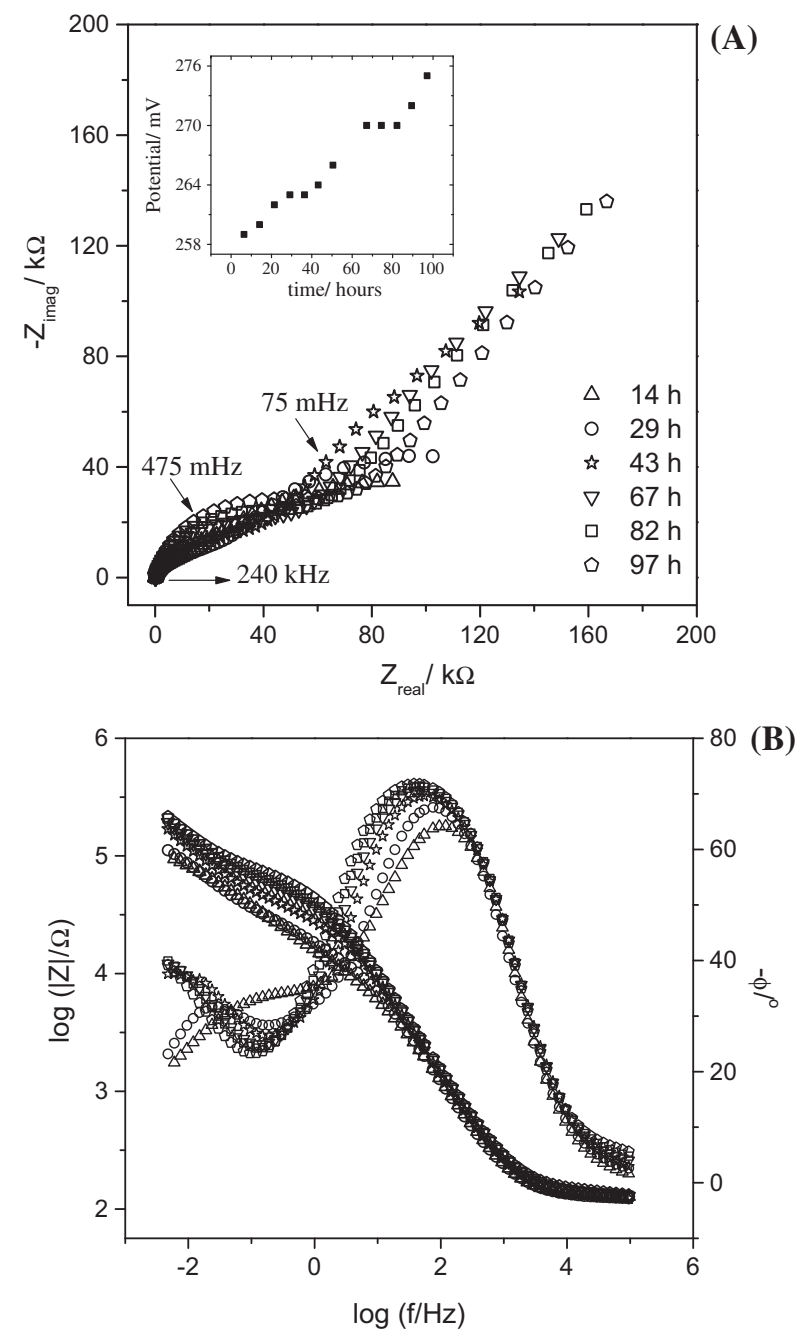

Fig. 8. (A) Experimental complex plane and (B) Bode modulus and phase angle plots for carbon paste electrodes modified with chalcopyrite in natural aerated salts solution containing $0.10 \mathrm{~mol} \mathrm{~L}^{-1}$ ferrous ions, recorded for $97 \mathrm{~h}$. Inset in (A): Open circuit potential vs. time. 
Fig. 7. The Bode phase angle plots (Fig. 8B) showed at least two time constants up to around $29 \mathrm{~h}$. The time constant at higher frequency had a phase angle of $\sim-70^{\circ}$, and a shift of the maximum from 100 to $40 \mathrm{~Hz}$ was related to the interfacial processes mentioned previously, which now also involved the reduction of $\mathrm{Fe}^{3+}$ species.

The time constant at LF showed a very low phase angle for $\mathrm{t}<30 \mathrm{~h}$, which could be attributed to the presence of a metallic oxide layer on the chalcopyrite surface, as already discussed. For $\mathrm{t}>43 \mathrm{~h}$, this time constant evolved to a diffusion feature, and was therefore now associated with the mass transfer of species (oxidized copper and iron ions) from the electrode surface. The diffusion process also became evident in the $|\mathrm{Z}|$ plots at low frequency values (Fig. 8B). These results suggested that for shorter times, the diffusion occurred within the pores of the native metallic oxidebased layer, while for longer times, the diffusion occurred from the electrode to the solution. Ghahremaninezhad et al. (2012) attributed this diffusive process to the transport of $\mathrm{Fe}^{3+} / \mathrm{Fe}^{2+}$ ions through the pores of the passive layer, which was probably rich in sulfur present on the surface of chalcopyrite. The electrode surface was not blocked, so the presence of a passive layer could not be assumed, as suggested elsewhere (Khoshkhoo et al., 2014a,b).

Subsequently, an assay with the chalcopyrite electrode was conducted using solution A containing $0.30 \mathrm{~mol} \mathrm{~L}^{-1}$ of ferrous ions. It can be seen from the inset in Fig. $9 A$ that the $E_{O C}$ value increased from 260 to $320 \mathrm{mV}$, due to the changes on the electrode surface and iron(II) oxidation by oxygen, as shown previously (Fig. 6A). The Nyquist plots showed a semicircle followed by a diffusion feature (Fig. 9A). The Bode phase angle plots (Fig. 9B) showed asymmetric peaks, with the maxima shifting to lower frequency values with time, followed by another time constant at low frequency. This shift was related to the increase of impedance associated with the charge transfer process, due to the surface modification that hindered chalcopyrite oxidation.

After the electrochemical experiment in the presence of iron(II) ions, the chalcopyrite-modified electrodes were thoroughly washed with solution A. The electrodes were then immersed in fresh solution A and new EIS measurements were immediately performed. The EIS diagrams (not shown) were found to be very similar to those obtained in the assays with the carbon pastechalcopyrite electrode in the absence of ferrous ions after $97 \mathrm{~h}$ of immersion. This suggested that iron hydroxide-sulfate or jarosite was partially or completely removed from the electrode surface by washing with solution A, explaining the similarity between the EIS diagrams. In a parallel experiment (not shown) under the same conditions, using a rotating chalcopyrite-modified carbon paste electrode at $1500 \mathrm{rpm}$, the amplitude of the capacitive semicircle decreased around 10-fold, indicating that the contribution of the iron oxide/hydroxide-based layer was less significant. This possibility is supported by the findings of Gu et al. (2013), who concluded that the hindering of chalcopyrite dissolution could not be attributed to the presence of jarosite, due to the ease with which it could be lost from the chalcopyrite surface.

As discussed in Section 4.2.1, Fe precipitation from ferrous solution should be in the form of jarosite or hydroxy-sulfate iron(III) salts, but due to the small amount of chalcopyrite in the chalcopyrite-modified carbon paste electrode, it was very difficult to separate and analyze the products. This was in contrast to the leaching and bioleaching processes (see below), where greater amounts of mineral were used and the residues could be easily analyzed.

\subsubsection{Chalcopyrite-modified carbon paste electrode in solution A} inoculated with At. ferrooxidans, in the absence and presence of $\mathrm{Fe}^{2+}$ ions

The studies in the presence of the bacteria were very different in nature, compared to the experiments described up to this point.

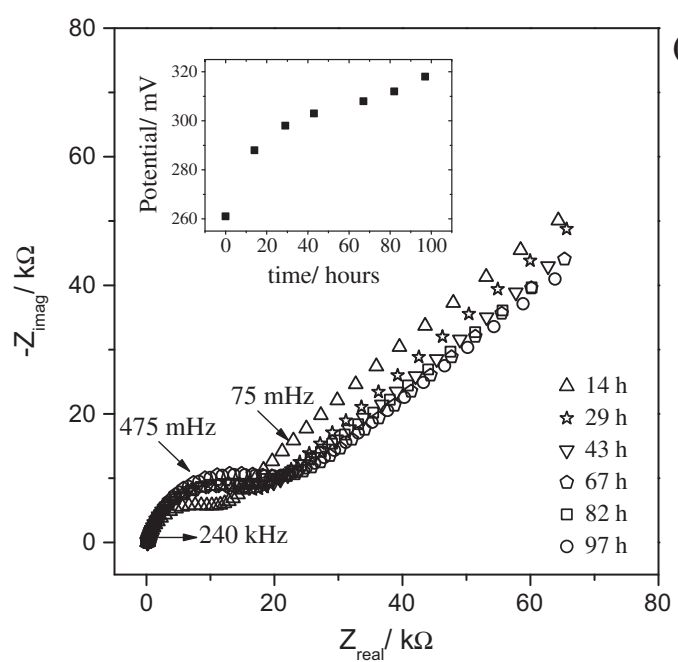

(A)

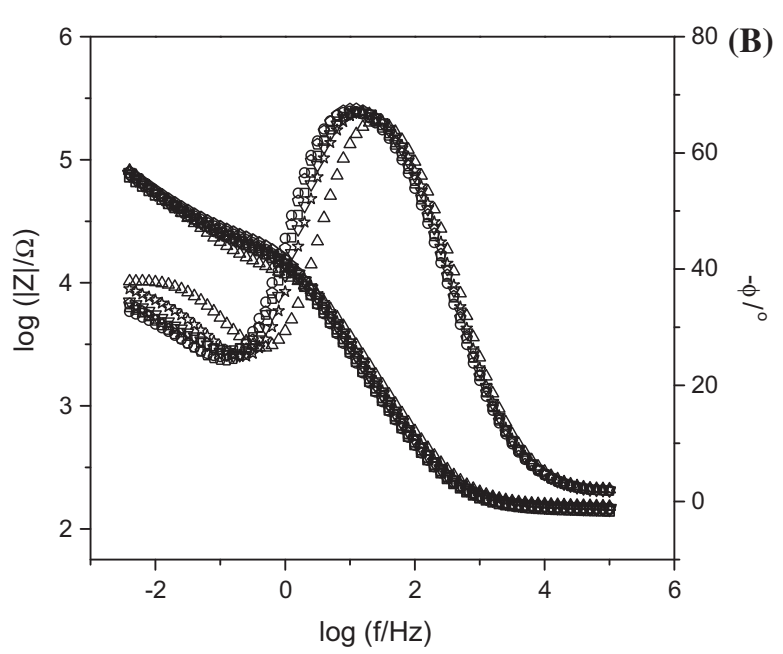

Fig. 9. (A) Experimental complex plane and (B) Bode modulus and phase angle plots for carbon paste electrodes modified with chalcopyrite in natural aerated salts solution containing $0.30 \mathrm{~mol} \mathrm{~L}^{-1}$ ferrous ions, recorded for $97 \mathrm{~h}$. Inset in (A): Open circuit potential vs. time.

The presence of the bacteria enabled the oxidation of ferrous ions in enzymatic reactions, drastically changing the ferric/ferrous ions ratio (Bevilaqua et al., 2004). Initially, bacteria attachment mainly occurs by electrostatic and then by hydrophobic interactions, and they are attached to sites with visible surface imperfections and/ or low degrees of crystallinity (Vera et al., 2013). The adhesion of bacteria to mineral surfaces occurs after around $3 \mathrm{~h}$ (Bevilaqua et al., 2003) and stimulates EPS production (Vera et al., 2013). The exopolysaccharide (EPS) distribution is not homogeneous and has been observed after three days of incubation (Bevilaqua et al., 2004). In this work, the biofilm reflected all the effects mediated by bacterial metabolism, including adhesion, EPS production, $\mathrm{Fe}^{2+}$ ions oxidation, mineral solubilization, and the formation of sulfur and jarosites. All these effects occur simultaneously and are almost impossible to evaluate individually from impedance diagrams. The complexity of the surface science involving EPS, attachment, and biofilm formation was recently reviewed by Vera et al. (2013).

Subsequent assays were conducted using the carbon paste/chalcopyrite electrode in the presence of the bacterium At. ferrooxidans in solution A without and with addition of iron(II) ions. Figs. 10-12 show the impedance plots obtained using solution $A$ without and with 0.10 and $0.30 \mathrm{~mol} \mathrm{~L}^{-1}$ ferrous ions, respectively. 
The insets in Figs. 10A, 11A, and 12A show the evolution of $E_{O C}$ over the period of the experiment $(\approx 97 \mathrm{~h})$ for all the conditions studied in the presence of the bacteria. It can be seen that the potential increased with the immersion time after $14 \mathrm{~h}$, as well as with the iron concentration. This indicated that the bacteria acted to increase the $\mathrm{Fe}^{3+}$ ions concentration in solution, due to the faster ferrous ions oxidation rate, compared to the rate with oxygen. The chalcopyrite surface also changed, with a shift of $E_{O C}$ to higher values.

In the absence of ferrous ions, and taking into consideration the design of the electrochemical cell, the influence of the bacteria on chalcopyrite dissolution was related to the quantity of bacteria attached to the electrode surface, and the amount of EPS could be assumed to be negligible, considering the conditions used to obtain the pellet (Gehrke et al., 1998) and the duration of the study period. Hence, in our systems containing ferrous ions, the main effect of the bacteria was expected to be the enzymatic production of ferric ions. The ferrous ions were completely oxidized within $48 \mathrm{~h}$, with the $\mathrm{Fe}^{3+} / \mathrm{Fe}^{2+}$ ratios reaching maxima for both 0.1 and $0.3 \mathrm{~mol} \mathrm{~L}^{-1} \mathrm{Fe}^{2+}$.

The impedance diagrams obtained in the presence of bacteria and absence of ferrous ions showed a well-defined capacitive semicircle in the middle frequency range, followed by a diffusion feature at LF (Fig. 10A). The semicircle was attributed to the charge transfer process, and the semicircle size increased with immersion time up to $43 \mathrm{~h}$. For $t \geqslant 67 \mathrm{~h}$, the semicircle size remained almost
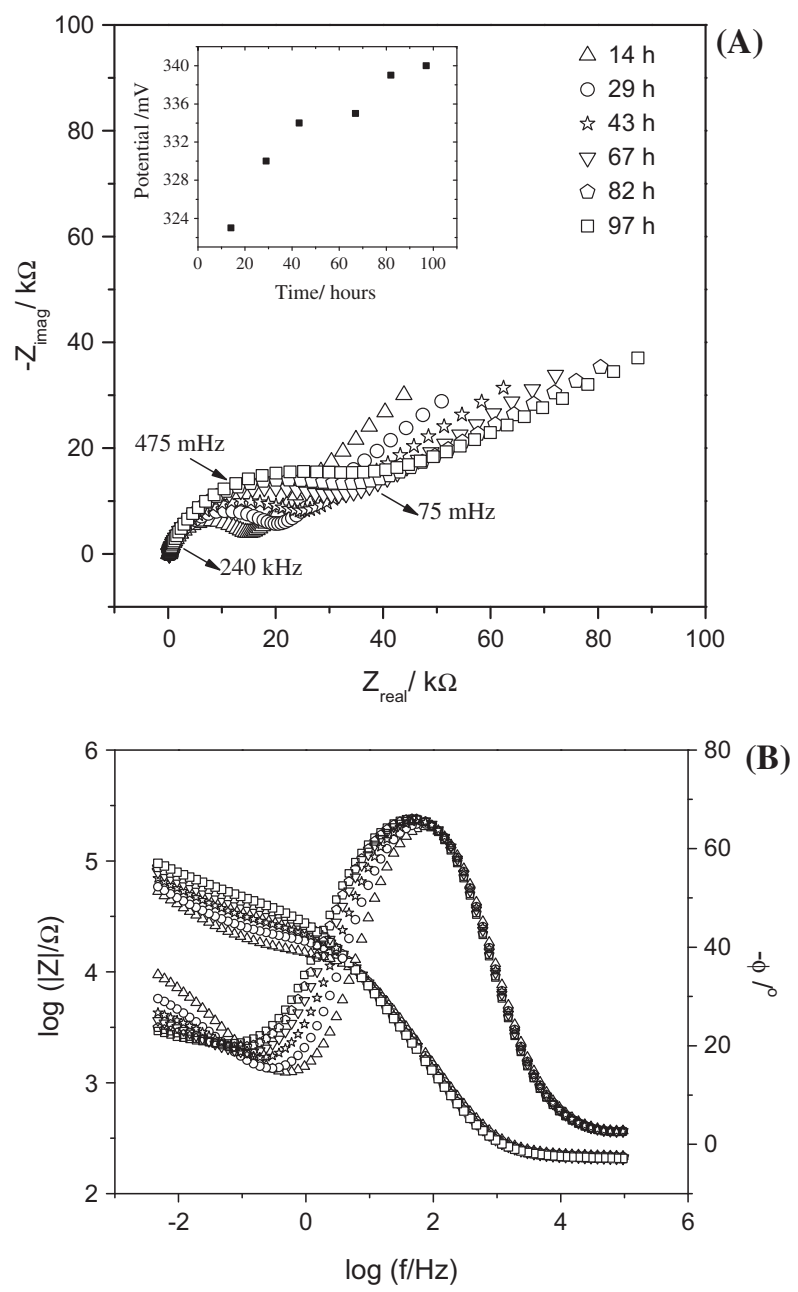

Fig. 10. (A) Experimental complex plane and (B) Bode modulus and phase angle plots for carbon paste electrodes modified with chalcopyrite in natural aerated salts solution in the presence of the bacteria At. ferrooxidans, recorded for $97 \mathrm{~h}$. Inset in (A): Open circuit potential vs. time.

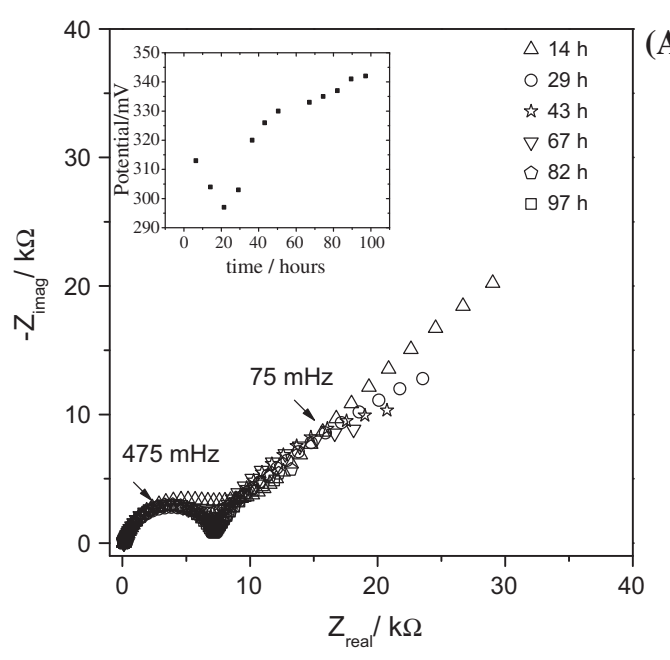

(A)

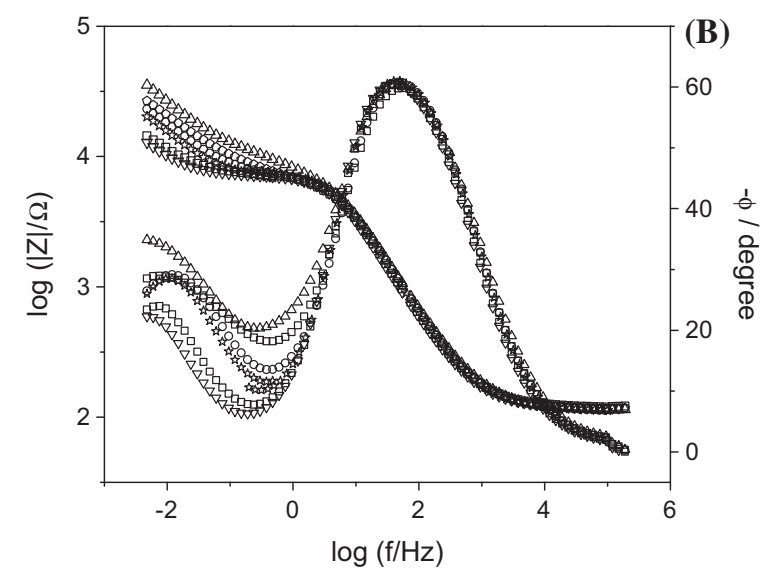

Fig. 11. (A) Experimental complex plane and (B) Bode modulus and phase angle plots for carbon paste electrodes modified with chalcopyrite in natural aerated salts solution with $0.10 \mathrm{~mol} \mathrm{~L}^{-1}$ ferrous ions in the presence of the bacteria $A t$ ferrooxidans, recorded for $97 \mathrm{~h}$. Inset in (A): Open circuit potential vs. time.

constant, indicating no significant changes in the rate of the charge transfer process. The presence of two time constants was confirmed by the Bode plots, where the diffusion feature at low frequencies was evidenced by the continuous increase of the $|\mathrm{Z}|$ values (Fig. 10B).

As mentioned above, in the presence of ferrous ions and bacteria, the fast enzymatic oxidation of iron(II) ions generated a highly oxidized solution, modifying the kinetics of chalcopyrite dissolution. Therefore, the action of the bacteria was expected to be more important in the solution than on the electrode surface. This was reflected in the impedance diagrams (Figs. 11 and 12). The complex plane plots (Figs. 11A and 12A) showed one capacitive semicircle followed by a diffusion feature at low frequency. The sizes of the capacitive semicircles were the smallest obtained using the chalcopyrite-modified electrodes. The Bode phase diagrams indicated the presence of at least two time constants, one in the medium frequency region, related to the charge transfer process involving the chalcopyrite/solution interface, and another at LF, associated with the mass transfer process (Figs. 11B and 12B). As iron(II) was rapidly oxidized by the bacteria, the $\mathrm{Fe}^{3+} / \mathrm{Fe}^{2+}$ ratio was $\gg 1$, so the cathodic reaction could also have involved the reduction of $\mathrm{Fe}^{3+}$ ions. The diffusion process was more evident at shorter times and seemed to be hindered at longer immersion times, as indicated by the decrease in the slope of the plots of $|\mathrm{Z}|$ against $\log \mathrm{f}$ (Figs. 11B and 12B). 


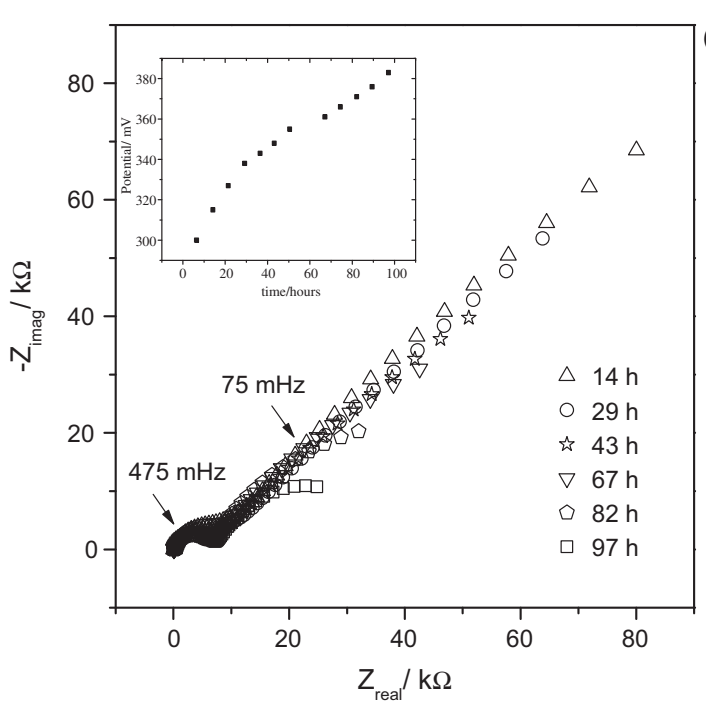

(A)

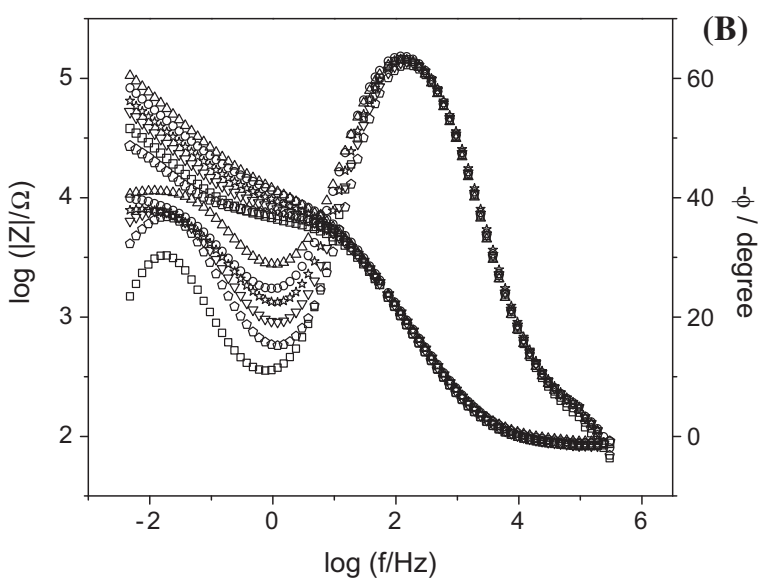

Fig. 12. (A) Experimental complex plane and (B) Bode modulus and phase angle plots for carbon paste electrodes modified with chalcopyrite in natural aerated salts solution with $0.30 \mathrm{~mol} \mathrm{~L}^{-1}$ ferrous ions in the presence of the bacteria At. ferrooxidans, recorded for $97 \mathrm{~h}$. Inset in (A): Open circuit potential vs. time.

Quantitative analysis of the experimental data was difficult due to the complexity of the electrode process for these systems. The presence of the live bacteria resulted in a dynamic and oxidizing system, with simultaneous influences on the electrode surface and the solution, while the chalcopyrite concomitantly presented an electrochemical response as well. During this complex process, copper and iron ions were found to be released from the mineral. Further complications arose from the possible formation of metal-deficient intermediates that were enriched in sulfur, and the formation of iron precipitates. The different processes occurring on the surface and in the solution were responsible for the changes observed at low frequencies. A biofilm containing iron oxide hydroxy-sulfate derivatives and bacteria (Gehrke et al., 1998) was formed on the electrode surface under these conditions.

The different models used to interpret the chalcopyrite dissolution by means of electrochemical measurements always considered the presence of a layer and/or chalcopyrite modification of the surface, and the results suggested that the nature and composition of these features changed according to the experimental conditions (such as the addition of ferrous ions and/or bacteria). These changes were observed in a relatively short time (a few days), compared to other assays such as bioleaching in shake flasks (which requires a month or longer).
Another complication in interpreting the results concerns the fact that the chalcopyrite leaching process is poorly understood at the molecular and atomic scale. The phenomena become even more complex when a living system is included. Consequently, other approaches and techniques have to be used in order to support electrochemical findings.

\subsection{Bioleaching and leaching studies}

Parallel bioleaching assays lasting 100 days were conducted using $0.10,0.20$, and $0.30 \mathrm{~mol} \mathrm{~L}^{-1} \mathrm{Fe}^{2+}$ ions, together with the corresponding abiotic assays. It is important to point out that bench scale bioleaching assays are well-established procedures. During the assays, the liquid phases were monitored by periodically measuring $\mathrm{pH}$, Eh, and the iron(II), iron(III), and copper concentrations, as described by Bevilaqua et al. (2004). For the first 2 weeks, the copper recovery was almost independent of the presence of the bacteria or iron(II) ions, while for longer times the results of bioleaching assays in the presence of iron(II) ions showed lower copper recovery than in the absence of bacteria (values of $17 \%$ and $73 \%$, respectively). The final bioleaching residues were analyzed by XRD, revealing the presence of chalcopyrite and the formation of jarosites, although no sulfur was detected.

The XRD analysis of the solid residue resulting from leaching in the presence of $0.10 \mathrm{~mol} \mathrm{~L}^{-1}$ ferrous ions revealed the presence of sulfur and jarosite as secondary phases (Fig. 13). This was indicative of the presence of a layer on the mineral surface after long immersion times. However, the liquid phase analysis showed copper release of $73 \%$, indicating that any layers present did not necessarily hinder the dissolution of chalcopyrite, in agreement with the literature (Gu et al., 2013). Additionally, it is worth stressing that the redox potential for the leaching assay was in the range $350-370 \mathrm{mV}$, corresponding to the optimal potential range for the maximization of copper recovery (Hiroyoshi et al., 2008a,b). It should also be noted that the dissolution of chalcopyrite releases iron and copper ions to the solution, which is favorable for further copper recovery.

Other conditions tested were with 0.20 and $0.30 \mathrm{~mol} \mathrm{~L}^{-1}$ ferrous ions, in order to complement the discussion of the EIS results. The XRD data showed the presence of jarosite and sulfur, but $90 \%$ (0.20 $\mathrm{mol} \mathrm{L}^{-1} \mathrm{Fe}^{2+}$ ions) and 78\% (0.30 $\mathrm{mol} \mathrm{L}^{-1} \mathrm{Fe}^{2+}$ ions) of copper were recovered using chemical conditions (without the presence of bacteria) after 100 days of monitoring, reinforcing the possibility of mineral dissolution even in the presence of precipitates ( $\mathrm{Gu}$ et al., 2013). The solid residues from the assay containing $0.20 \mathrm{~mol} \mathrm{~L}^{-1}$ ferrous ions were analyzed using FEG, where sulfur phases were

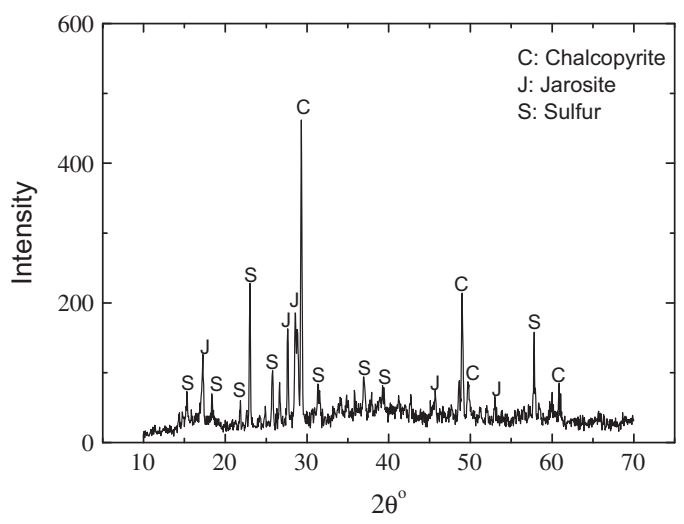

Fig. 13. X-ray diffractogram for a leaching (abiotic process) residue obtained after 100 days in the presence of $0.10 \mathrm{~mol} \mathrm{~L}^{-1}$ ferrous ions. 

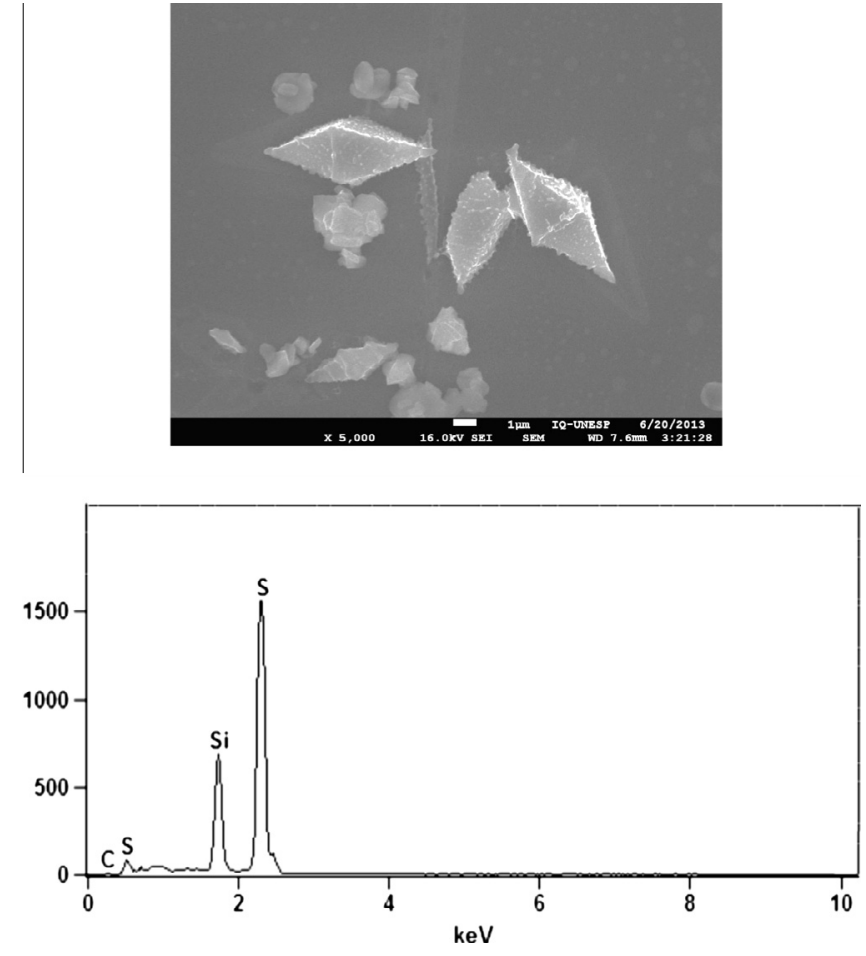

Fig. 14. FEG image and the corresponding EDS spectrum for the leaching assay using the salts solution in the presence of $0.20 \mathrm{~mol} \mathrm{~L}^{-1}$ ferrous ions for 100 days. $\mathrm{Si}$ originated from the silica in the mineral sample.

detected, showing that the mineral could still be dissolved in the presence of a sulfur layer (Fig. 14).

The results obtained in this work do not support the hypothesis of passive film formation that could impede the dissolution of chalcopyrite, reinforcing the notion that the slow dissolution of chalcopyrite was due to a mechanism other than surface passivation. In very recent work, Crundwell (2015) suggested that the slow dissolution of chalcopyrite could be explained based on its n-type semiconductor behavior. According to this mechanism, chalcopyrite dissolution can only occur when the Fermi level and the valence band achieve the same value at the electrode surface, which occurs for overpotentials higher than $0.6 \mathrm{~V}$. In the potential region from about -0.2 to $+0.5 \mathrm{~V} / \mathrm{Ag} / \mathrm{AgCl} / \mathrm{KCl}_{\text {sat }}$, the anodic current is very low and chalcopyrite dissolution does not occur. This has sometimes been interpreted as a passive region, which means that a passive film should be present. Studies in progress in our laboratory aim to confirm the applicability of the Crundwell model, and we hope to be able to continue to deepen understanding of the mechanisms involved in chalcopyrite dissolution. We have observed that there is no film growth when applying a potential from -0.2 to $+0.5 \mathrm{~V} / \mathrm{Ag} / \mathrm{AgCl} / \mathrm{KCl}_{\text {sat }}$. The Crundwell model also predicts that iron should be dissolved before copper, as supported by previous observations (Bevilaqua et al., 2004).

\section{Conclusions}

Chalcopyrite-modified carbon paste electrodes were studied in the presence and absence of At. ferrooxidans and ferrous ions in solution A of T\&K medium for around one hundred hours. Leaching and bioleaching assays were also performed for longer immersion times, and the solutions and residues were analyzed to obtain information about chalcopyrite dissolution and modifications of the mineral surface. The results allowed the following conclusions to be drawn:
Comparison with leaching and bioleaching processes showed that electrochemical impedance spectroscopy provides a powerful tool for inferring the behavior of chalcopyrite-modified carbon paste electrodes.

The initial process of chalcopyrite dissolution was chemical/ electrochemical attack on the native oxide layer present on the surfaces of the mineral particles, and the dissolution was accelerated in the presence of both ferrous ions and bacteria. The increased oxidizing power of the solution containing both ferrous ions and bacteria strongly decreased the charge transfer resistance of the chalcopyrite-modified electrodes.

In the absence of ferrous ions in the solution, At. ferrooxidans had a low influence on the chalcopyrite-modified electrodes, due to the small quantity of bacteria that could become attached to the electrode surface.

New phases were formed as a function of time, due to the further oxidation/reduction of chalcopyrite. These new phases were sulfur, jarosite, biofilm, and a surface enriched with metaldeficient sulfides and/or iron hydroxy-sulfate species. These new phases were not able to completely halt chalcopyrite dissolution, because in many cases they were removed from the surface during rotation of the electrode. Nonetheless, a slow increase in impedance with time was indicative of further modification of the chalcopyrite surface.

The presence of ferrous ions caused turbidity of the solution, and depending on their concentration, there appeared to the formation a gel-like film or a layer based on iron hydroxide-sulfate. The formation of a biofilm was indicated in the presence of ferrous ions and bacteria.

In the presence of ferrous ions, the solid residues of leaching showed the presence of sulfur and jarosite, while only jarosite was detected after bioleaching. The presence of the ferrous ions accelerated the dissolution of chalcopyrite.

\section{Acknowledgements}

The authors gratefully acknowledge financial support and scholarships provided by the Brazilian funding agencies $\mathrm{CNPq}$ (AVB proc. no. 305890/2010-7), CAPES, and FAPESP (FAA proc. no. 2010/13089-1 and DB proc. 2011/19868-5). The authors thank LMA-IQ for SEM/EDXS analyses.

\section{References}

Ahmadi, A., Schaffie, M., Petersen, J., Schippers, A., Ranjbar, M., 2011. Conventional and electrochemical bioleaching of chalcopyrite concentrates by moderately thermophilic bacteria at high pulp density. Hydrometallurgy 106, 84-92. http:// dx.doi.org/10.1016/j.hydromet.2010.12.007.

Baes Jr., C.F., Mesmer, R.E., 1976. The Hydrolysis of Cations. John Wiley \& Sons, New York, p. 226.

Barron, J.L.C., Lueking, D.R., 1990. Growth and maintenance of Thiobacillus ferrooxidans cells. Appl. Environ. Microbiol. 56, 2801.

Bevilaqua, D., Diéz-Perez, I., Fugivara, C.S., Sanz, F., Benedetti, A.V., Garcia Jr, O., 2004. Oxidative dissolution of chalcopyrite by Acidithiobacillus ferrooxidans analyzed by electrochemical impedance spectroscopy and atomic force microscopy. Bioelectrochemistry 64, 79-84. http://dx.doi.org/10.1016/j. bioelechem.2004.01.006.

Bevilaqua, D., Diéz-Perez, I., Fugivara, C.S., Sanz, F., Garcia Jr., O., Benedetti, A.V. 2003. Characterization of bornite (Cu5FeS4) electrodes in the presence of the bacterium Acidithiobacillus ferrooxidans. J. Braz. Chem. Soc. 14, 637. http://dx. doi.org/10.1590/S0103-50532003000400022.

Bevilaqua, D., Garcia Jr, O., Tuovinen, O.H., 2010. Oxidative dissolution of bornite by Acidithiobacillus ferrooxidans. Process Biochem. 45, 101-106. http://dx.doi.org/ 10.1016/j.procbio.2009.08.013.

Bevilaqua, D., Lahti, H., Suegama, P.H., Garcia Jr, O., Benedetti, A.V., Puhakka, J.A., Tuovinen, O.H., 2013. Effect of Na-chloride on the bioleaching of a chalcopyrite concentrate in shake flasks and stirred tank bioreactors. Hydrometallurgy 138, 1-13. http://dx.doi.org/10.1016/j.hydromet.2013.06.008.

Bevilaqua, D., Leite, A.L.L.C., Garcia Jr, O., Tuovinen, O.H., 2002. Oxidation of chalcopyrite by Acidithiobacillus ferrooxidans and Acidithiobacillus thiooxidans in shake flasks. Process Biochem. 38, 587-592. http://dx.doi.org/10.1016/S00329592(02)00169-3. 
Córdoba, E.M., Muñoz, J.A., Blázquez, M.L., González, F., Ballester, A., 2008. Leaching of chalcopyrite with ferric ion. Part II: Effect of redox potential. Hydrometallurgy 93, 88-96. http://dx.doi.org/10.1016/j.hydromet.2008.04.016.

Crundwell, F.K., 2013. The dissolution and leaching of minerals: mechanisms, myths and misunderstandings. Hydrometallurgy 139, 132-148. http://dx.doi.org/ 10.1016/j.hydromet.2013.08.003.

Crundwell, F.K., 2015. The semiconductor mechanism of dissolution and the pseudo-passivation of chalcopyrite. Can. Metall. Q. 54, 279-288. http://dx.doi. org/10.1179/1879139515Y.0000000007.

Ferreira, A.A.P., Ribeiro, S.J.L., Fugivara, C.S., Caiut, J.M.A., Sargentelli, V., Benedetti, A. V., 2011. Eletrodo de pasta de carbono em minicavidade de contato sólido. Eclética Química 36, 183.

Gahan, C.S., Srichandan, H., Kim, D., Akcil, A., 2012. Biohydrometallurgy and biomineral processing technology; a review on past, present and future research. J. Recent Sci. 1, 85-99.

Garcia Jr, O., 1991. Isolation and characterization of Acidithiobacillus thiooxidans and Acidithiobacillus ferrooxidans from mineral mines. Revista Brasileira de Microbiologia 20, 1.

Gehrke, T., Telegdi, J., Thierry, D., Sand, W., 1998. Importance of extracellular polymeric substances from Thiobacillus ferrooxidans for bioleaching. Appl. Environ. Microbiol. 64, 2743.

Ghahremaninezhad, A., Dixon, D.G., Asselin, E., 2012. Kinetics of the ferricferrous couple on anodically passivated chalcopyrite $\left(\mathrm{CuFeS}_{2}\right)$ electrodes. Hydrometallurgy 125-126, 42-49. http://dx.doi.org/10.1016/j.hydromet.2012. 05.004 .

Gotic, M., Music, S., 2007. Mössbauer FT-IR and FE SEM investigation of iron oxides precipitated from $\mathrm{FeSO}_{4}$ solutions. J. Mol. Struct. 834-836, 445-453. http://dx. doi.org/10.1016/j.molstruc.2006.10.059.

Gu, G., Hu, K., Zhang, X., Xiong, X., Yang, H., 2013. The stepwise dissolution of chalcopyrite bioleached by Leptospirillum ferriphilum. Electrochim. Acta 103, 50-57. http://dx.doi.org/10.1016/j.electacta.2013.04.051.

Hackl, R.P., Dreisinger, D.B., Peters, E., King, J.A., 1995. Passivation of chalcopyrite during oxidative leaching in sulfate media. Hydrometallurgy 39, 25-48. http:// dx.doi.org/10.1016/0304-386X(95)00023-A.

Hiroyoshi, N., Kitagawa, H., Tsunekawa, M., 2008a. Effect of solution composition on the optimum redox potential for chalcopyrite leaching in sulfuric acid solutions. Hydrometallurgy 91, 144-149. http://dx.doi.org/10.1016/j.hydromet.2007.12. 005.

Hiroyoshi, N., Tsunekawa, M., Okamoto, H., Nakayama, R., Kuroiwa, S., 2008b. Can. Metall. O 47, 253.

Holmes, P.R., Crundwell, F.K., 2013. Polysulfides do not cause passivation: results from the dissolution of pyrite and implications for other sulfide minerals. Hydrometallurgy 139, 101-110. http://dx.doi.org/10.1016/j.hydromet.2013.07. 006.

Horta, D.G., Bevilaqua, D., Acciari, H.A., Garcia Júnior, O., Benedetti, A.V., 2009. Optimization of the use of carbon paste electrodes (CPE) for electrochemical study of the chalcopyrite. Quim. Nova 32, 1734.

Khoe, G.H., Robins, R.G., 1988. The complexation of iron(III) with sulphate, phosphate, or arsenate ion in sodium nitrate medium at $25^{\circ} \mathrm{C}$. J. Chem. Soc. Dalton Trans., 2015-2021

Khoshkhoo, M., Dopson, M., Shchukarev, A., Sandström, Å., 2014a. Chalcopyrite leaching and bioleaching: an X-ray photoelectron spectroscopic (XPS) investigation on the nature of hindered dissolution. Hydrometallurgy 149, 220-227. http://dx.doi.org/10.1016/j.hydromet.2014.08.012.

Khoshkhoo, M., Dopson, M., Shchukarev, A., Sandström, Å., 2014b. Electrochemical simulation of redox potential development in bioleaching of a pyritic chalcopyrite concentrate. Hydrometallurgy 144-145, 7-14. http://dx.doi.org/ 10.1016/j.hydromet.2013.12.003.

Klauber, C., 2008. A critical review of the surface chemistry of acidic ferric sulphate dissolution of chalcopyrite with regards to hindered dissolution. Int. J. Miner Process. 86, 1-17. http://dx.doi.org/10.1016/j.minpro.2007.09.003.
Lara, R., García-Meza, J.V., González, I., Cruz, R., 2013. Influence of the surface speciation on biofilm attachment to chalcopyrite by Acidithiobacillus thiooxidans. Appl. Microbiol. Biotechnol. 97, 2711-2724. http://dx.doi.org/ 10.1007/s00253-012-4099-8.

Li, Y. Kawashima, N., Li, J. Chandra, A.P., Gerson, A.R., 2013. A review of the structure, and fundamental mechanisms and kinetics of the leaching of chalcopyrite. Adv. Colloid Interface Sci. 197-198, 1-32. http://dx.doi.org/ 10.1016/j.cis.2013.03.004

Majuste, D., Ciminelli, V.S.T., Osseo-Asare, K., Dantas, M.S.S., Magalhães-Paniago, R., 2012. Electrochemical dissolution of chalcopyrite: detection of bornite by synchrotron small angle X-ray diffraction and its correlation with the hindered dissolution process. Hydrometallurgy 111-112, 114-123. http://dx.doi.org/ 10.1016/j.hydromet.2011.11.003.

Monteiro, V.F., Garcia Jr., O., Tuovinen, O.H., 1999. Oxidative dissolution of covellite by Thiobacillus ferrooxidans. In: Amils, R., Ballester, A. (Eds.), Process Metallurgy. Elsevier, pp. 283-290. http://dx.doi.org/10.1016/S1572-4409(99) 80028-5.

Nava, D., González, I., Leinen, D., Ramos-Barrado, J.R., 2008. Surface characterization by X-ray photoelectron spectroscopy and cyclic voltammetry of products formed during the potentiostatic reduction of chalcopyrite. Electrochim. Acta 53, 4889-4899. http://dx.doi.org/10.1016/j.electacta.2008.01.088.

Parida, K., Das, J., 1996a. Studies on ferric oxide hydroxides: II. Structural properties of goethite samples $(\alpha-\mathrm{FeOOH})$ prepared by homogeneous precipitation from $\mathrm{Fe}$ $\left(\mathrm{NO}_{3}\right)_{3}$ solution in the presence of sulfate ions. J. Colloid Interface Sci. 178, 586593. http://dx.doi.org/10.1006/jcis.1996.0155.

Parida, K., Das, J., 1996b. Studies of ferric oxide hydroxides. Part I. Effect of sulfate ions on the formation and physico-chemical properties of ferric oxide hydroxides prepared by a homogeneous precipitation method. J. Mater. Sci. 31, 2199-2205. http://dx.doi.org/10.1007/BF00356646.

Qin, W., Yang, C., Lai, S., Wang, J., Liu, K., Zhang, B., 2013. Bioleaching of chalcopyrite by moderately thermophilic microorganisms. Bioresour. Technol. 129, 200-208. http://dx.doi.org/10.1016/j.biortech.2012.11.050.

Sandström, Å., Shchukarev, A., Paul, J., 2005. XPS characterisation of chalcopyrite chemically and bio-leached at high and low redox potential. Miner. Eng. 18, 505-515. http://dx.doi.org/10.1016/j.mineng.2004.08.004.

Sasaki, K., Nakamuta, Y., Hirajima, T., Tuovinen, O.H., 2009. Raman characterization of secondary minerals formed during chalcopyrite leaching with Acidithiobacillus ferrooxidans. Hydrometallurgy 95, 153-158. http://dx.doi.org/ 10.1016/j.hydromet.2008.05.009.

Sasaki, K., Tsunekawa, M., Ohtsuka, T., Konno, H., 1998. The role of sulfur-oxidizing bacteria Thiobacillus thiooxidans in pyrite weathering. Colloids Surf. A 133, 269278. http://dx.doi.org/10.1016/S0927-7757(97)00200-8.

Third, K.A., Cord-Ruwisch, R., Watling, H.R., 2002. Control of the redox potential by oxygen limitation improves bacterial leaching of chalcopyrite. Biotechnol. Bioeng. 78, 433-441. http://dx.doi.org/10.1002/bit.10184.

Tuovinen, O.H., Kelly, D.P., 1973. Studies on the growth of Thiobacillus ferrooxidans. I. Use of membrane filters and ferrous iron agar to determine viable numbers, and comparison with ${ }^{14} \mathrm{CO}_{2}$ fixation and iron oxidation as measures of growth. Arch. Microbiol. 88, 285.

Vera, M., Schippers, A., Sand, W., 2013. Progress in bioleaching: fundamentals and mechanisms of bacterial metal sulfide oxidation. Mini Rev. Appl. Microbiol. Biotechnol. 97, 7529-7541.

Verbaan, B., Crundwell, F.K., 1986. An electrochemical model for the leaching of a sphalerite concentrate. Hydrometallurgy 16, 345-359. http://dx.doi.org/ 10.1016/0304-386X(86)90009-5.

Zhao, H., Wang, J., Qin, W., Hu, M., Zhu, S., Qiu, G., 2015. Electrochemical dissolution process of chalcopyrite in the presence of mesophilic microorganisms. Miner. Eng. 71, 159-169. http://dx.doi.org/10.1016/j.mineng.2014.10.025. 